Center for Computational Sciences

\title{
GRAIND CHALLENGE PROBLEMS IN \\ ENVIRONMENTAL MODELING AND REMEDIATION: \\ GROUNDWATER CONTAMINANT TRANSPORT \\ FINAL PROJECT REPORT 1998
}

\author{
Partnership in Computational Sciences Consortium * \\ * Center for Computational Sciences \\ Bldg 4500N, MS 6203 \\ Oak Ridge National Laboratory \\ Oak Ridge, TN 37831.
}

Date Published: April 1998

The submitted nanuscript has been authored by a contractor of the U.S. Government under contract No. DE-AC05-96OR22464. Accordingly, the U.S. Government retains a nonexclusive, royalty-free license to publish or reproduce the published form of this contribution, or allow others to do so, for U.S. Government purposes.

Prepared by the

Oak Ridge National Laboratory

Oak Ridge, Tennessee 37831

managed by

Lockheed Martin Energy Research Corp.

for the

U.S. DEPARTMENT OF ENERGY

under Contract No. DE-AC05-96OR22464

MASTER

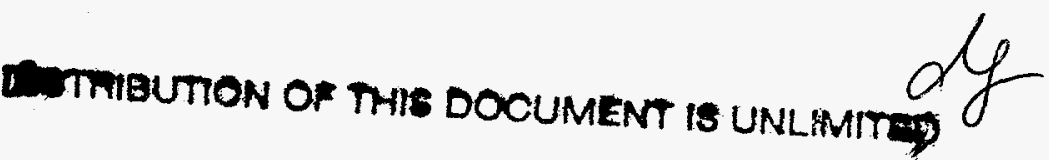




\section{DISCLAIMER}

This report was prepared as an account of work sponsored by an agency of the United States Government. Neither the United States Government nor any agency thereof, nor any of their employees, make any warranty, express or implied, or assumes any legal liability or responsibility for the accuracy, completeness, or usefulness of any information, apparatus, product, or process disclosed, or represents that its use would not infringe privately owned rights. Reference herein to any specific commercial product, process, or service by trade name, trademark, manufacturer, or otherwise does not necessarily constitute or imply its endorsement, recommendation, or favoring by the United States Government or any agency thereof. The views and opinions of authors expressed herein do not necessarily state or reflect those of the United States Government or

any agency thereof. 


\section{DISCLAIMER}

Portions of this document may be illegible electronic image products. Images are produced from the best available original document. 


\section{Contents}

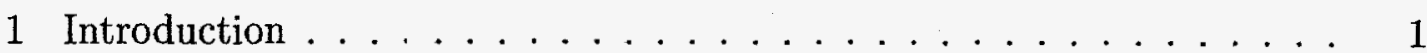

2 Deliverables ...................... 3

3 Texas A\&M University . . . . . . . . . . . . . . 4

3.1 Code Developement . . . . . . . . . . . . . . . . 4

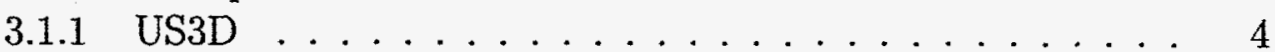

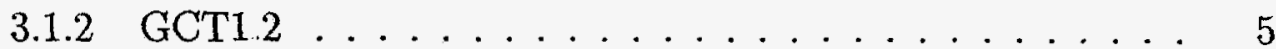

3.1.3 GCT1.3 Two-Phase Flow Model . . . . . . . . . . . . 6

3.2 Solution Techniques . . . . . . . . . . . . . . . . 7

3.3 Parameter Estimation . . . . . . . . . . . . 8

3.4 References . . . . . . . . . . . . . . 9

3.5 Publications Resulting from DOE Grant DE-FG03-95ER25263 . . 9

4 State University of New York at Stony Brook . . . . . . . . 14

4.1 Code Develorment . . . . . . . . . . . . . . . . . 14

$4.2 \quad$ Field Applications . . . . . . . . . . . . . . . . . . . . 15

4.3 Parameter Estimation . . . . . . . . . . . . . . . . 17

4.4 Publications Resulting from DOE Grant DE-FG02-95ER25265 . . 19

5 University of South Carolina . . . . . . . . . . . . . 20

5.1 Numerical Algorithms for Advection-Diffusion-Reaction Equations - ELLAM . . . . . . . . . . . . . . . 20

5.2 Input Modules for GCT $1.3 \ldots \ldots \ldots \ldots \ldots \ldots . \ldots . \ldots 21$

5.3 Graphical User Interfaces for Model Development and Analysis . . 21

5.4 Tracking/Steering Library . . . . . . . . . . . . . . . . . . 22

5.5 Data Compression . . . . . . . . . . . . . . . 23

5.6 Field Applica.tion Simulations . . . . . . . . . . . . . 24

5.7 Publications Resulting from DOE Grant DE-FG05-95ER25266 . . 26

6 Brookhaven National Laboratory . . . . . . . . . . . . . . 27

6.1 Code Develojment . . . . . . . . . . . . . . . 27

6.2 Code Management . . . . . . . . . . . . . . . . . . . 28

6.3 Field Application . . . . . . . . . . . . . . . . . . . . . . 28

6.4 User Interface . . . . . . . . . . . . . . . . . . . . . . . . . . 28

7 Oak Ridge National Laboratory $\ldots \ldots \ldots \ldots$

7.1 Code Management and Testing of GCT . . . . . . . . . 30

7.2 DOLIB/DONIO Library Development . . . . . . . . . . . 30

7.3 Adaptive Triangulation for Strongly Anisotropic Problems . . . 31

7.4 Investigation of Parallel Iterative Solvers for Groundwater Flow and Transport Problems 
7.5 Biogeochemistry Applications and Testing . . . . . . . . . 31

7.6 Other Groundwater Code Developments . . . . . . . . . . . 32

7.6 .1 PFEM . . . . . . . . . . . . . . . 33

7.6 .2 PGREM3D $\ldots \ldots \ldots \ldots \ldots \ldots \ldots \ldots \ldots$

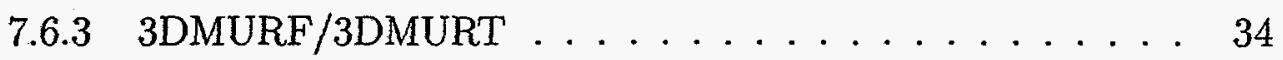

8 Princeton University . . . . . . . . . . . . . . . . 36

8.1 Princeton Accomplishments .............. . . 36

8.2 Risk Assessment and Quantification for Complex Mixtures . . . 37

8.3 Development of Three-dimensional ELLAM Algorithms . . . . . . 39

8.4 A Computational Investigation of the Fractional Flow Formulation for Infiltration Problems . . . . . . . . . . . . . . 40

8.5 Field Applications . . . . . . . . . . . . . . . . 41

8.6 Publications Resulting from DOE Grant . . . . . . . . . 42

9 The University of Texas . . . . . . . . . . . . . . . 44

9.1 The Parssim 1 and GCT simulators . . . . . . . . . . 45

9.1.1 Algorithm and Software Development for Flow . . . . . . 47

9.1.2 Algorithm and Software Development for Transport . . . . 48

9.1.3 Algorithm and Software Development for Geochemistry . . 50

9.1.4 Docunentation and User Interface Software Development . 51

9.1.5 A Scripting Language for GCT . . . . . . . . . . 52

9.2 The Eye Visualization Tool . . . . . . . . . . . . . . . . 53

9.3 Model Applications . . . . . . . . . . . . . . . . . . . 54

9.3.1 Benchmark Problems . . . . . . . . . . . . . . 55

9.3 .2 Site Characterization . . . . . . . . . . . . . 56

9.3.3 Radionuclide migration . . . . . . . . . . . . . 56

9.3.4 Pump-and-treat Remediation Simuiation . . . . . . . . 56

9.3.5 Well Sitimulation . . . . . . . . . . . . . 57

9.3 .6 Diagenesis . . . . . . . . . . . . . . . 58

9.3.7 Biotic/Abiotic Competition . . . . . . . . . . 58

9.3 .8 Bioremediation . . . . . . . . . . . . . 59

9.4 Prospective Model Applications . . . . . . . . . . . . 60

9.4.1 Heavy Metal Transport . . . . . . . . . . . . . . . . . 61

9.4 .2 Coal Ash Leaching . . . . . . . . . . . . . 61

9.5 Refereed Pullications . . . . . . . . . . . . . . . . . . 61

9.6 Other Publications . . . . . . . . . . . . . . . . . . 63

9.7 Technical Reports . . . . . . . . . . . . . . . . . . 66

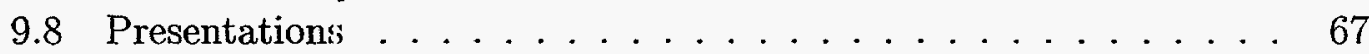

9.9 References . . . . . . . . . . . . . . . . . . 80 


\title{
GRAND CHALLENGE PROBLEMS IN ENVIRONMEINTAL MODELING AND REMEDIATION: GROUNDWATER CONTAMINANT TRANSPORT FINAL PROJECT REPORT 1998
}

\author{
Partnership in Computational Sciences Consortium
}

\begin{abstract}
The over-reaching goal of the Groundwater Grand Challenge component of the Partnership in Computational Science (PICS) was to develop and establish the massively parallel approach for the description of groundwater flow and transport and to address the problem of uncertainties in the data and its interpretation. This necessitated the development of innovative algorithms and the implementation of massively parallel computational toois to provide a suite of simulators for groundwater flow and transport in heterogereous media. This report summarizes the activities and deliverables of the Groundwater Grand Challenge project funded through the High Performance Computing grand challenge program of the Department of Energy from 1995 through 1997.

Seven institutions were primarily involved in this project: Brookhaven National Laborał;ory, Oak Ridge National Laboratory, Princeton University, SUNY at Stony Brook, Texas A\&M University, The University of South Carolina, and the University of Texas at Austin, with contributing efforts from the Westinghouse Savannah River Technology Center. Each institution had primary responsibility for specific research components, but strong collaboration among all institutions was essential for the success of the project and in producing the final deliverables.
\end{abstract}


PICS deliverables include source code for the suite of research simulators and auxiliary HPC tools, associated documentation, and test problems. These materials will be available as indicated from each institution's web page or from the Center for Computational Sciences Oak Ridge National Laboratory. 


\section{Introduction}

The groundwater grand challenge component of the Partnership in Computational Science (PICS) High Performance Computing initiative was formed to apply the members' collective efforts towards the mathematical and scientific challenges presented by complex groundwater, soil, contaminants, and air interactions. The numerical modeling of the fate of groundwater contaminants is a critical step in the formulation of remediation policies to be used to address contaminated groundwater and soils. Such strategies as pump-and-treat and in-situ vitrification require accurate knowledge of the location and extent of the contaminant plume; furthermore, some remediation strategies themselves use complex physical and chemical processes, requiring, for example, the placement of chemical "traps" or the injection of surfactants, bacteria, or nutrients.

Remediation methods remain extremely expensive and unpredictable in their success. This is due to a number of factors, including significant geologic heterogeneity, incomplete characterization of the subsurface, and the complexity of underground contaminant reactions and remediation processes.

Groundwater contamination problems typically involve organic liquids, ionic solutes, and/or radionuclides. The transfer of chemical species between the contaminant-bearing ?hase, the soil or aquifer, and the groundwater may involve interphase mass transfer as well as a host of intraphase chemical reactions such as dissolution, aqueovs phase complexation, ion exchange, adsorption, precipitation, oxidation/reduction, and even biological degradation kinetics. The extent of mass transfer and chemical reaction is ultimately limited by thermodynamic equilibrium, but compositions far from equilibrium often arise locally because of kinetic and surface area constraints.

In addition to the basic research on coupled multi-phase flow and multicomponent transport in porous media, the development of parallel algorithms for the solution of these coupled equations, and the development of computational science tools for better analysis and understanding, specific deliverables provided an overriding guide for the collaborative work among consortium members. 
This report summarizes the activities and deliverables of the Groundwater Grand Challenge project funded through the High Performance Computing grand challenge program of the Department of Energy from 1995 through 1997. The goals of the project are to develop and establish the massively parallel approach for the description of g:oundwater flow and transport and to address the problem of uncertainties in the data and its interpretation. This required the development of innovative algorithms and the implementation of massively parallel computational tools to provide a suite of simulators for groundwater flow and transport in heterogeneous media.

Seven primary institutions were involved in this project: Brookhaven National Laboratory, Oak Ridge National Laboratory, Princeton University, SUNY at Stony Brook, Texas A\&M University, The University of South Carolina, and the University of Texess at Austin. Each institution had primary responsibility for specific research components as outlined in each institution's section of this report, but strong collaboration among institutions was essential for the success of the project and in producing the final deliverables.

PICS deliverables include source code for the suite of research simulators and auxiliary HPC tools, associated documentation, and test problems. These materials will be available from each institation's web page or from the Center for Computational Sciences Oak Ridge National Laboratory. 


\section{Deliverables}

PICS deliverables include source code for the suite of research simulators and auxiliary HPC tools, associated documentation, and test problems. These materials will be available from each institution's web page or from the Center for Computational Sciences Oak Ridge National Laboratory.

- GCT1.2: Saturated/Unsaturated flow and multicomponent transport; How based on Galerkin FEM and transport based on mixed method of characteristics and Godunov schemes.

(http://www.ccs.ornl.gov/GC/gw/gw.html)

- GCT1.3: Two-phase flow and multicomponent transport. (http://www.isc.tamu.edu/JEP/tsun/pics/PicsCode.html)

- G3D: Graphical pre- and post-processing software. (http://www.math.sc.edu/sharpley/G3D/colormanual.ps)

- Steer: Steering and tracking Library. (http://www.math.sc.edu/sharpley/Steer.html)

- Parsimm: Single-phase flow, radionuclide decay, and biogeochemistry.

- EDONIO/DOLIB: Scalable I/O library and parallel distributed object library. (http://wvw.epm.orni.gov/efdazedo/softtools.htm)

- PERST: Param€ter estimation. (http://www.ams.sunysb.edu/lindquis/pics.html)

- US3D-MP: Saturated/Unsaturated flow and single component transport based on Galerkin FEM (http://www.isc.tamu.edu/PICS/us3d-mp)

- 2D Front tracking code from SUNY-SB. (http://www.ams.sunysb.edu/shock/FTdoc/FTmain.html)

- Parssim1: The Parallel Subsurface Simulator, Single Phase. Single-phase flow, multi-component transport, and multi-phase geochemistry, including a full complement of homogeneous and heterogeneous reactions (complexation, adsorption, ion-exchange, precipitation/dissolution, biological Monod, and radionuclide) of both equilibrium and kinetic type. (http://www.ticam.utexas.edu/Groups/SubSurfMod/software.html) 
- Eye: 3D visualization tool.

(http://www.ticam.utexas.edu/Groups/SubSurfMod/software.html)

\section{Texas A\&M University}

Texas A\&M contributed primarily in algorithms and code development for computer simulation of multiphase flows. In parallel with the extensive code development effort, we concent rated our work on the following areas: (1) extensive testing and verification of the existing codes on analytic solutions; (2) development of a library of solution techniques and preconditioners, including a Lagrange multiplier option; and (3) techniques for treating the non-linearities in the saturation and coupled system.

\subsection{Code Developement}

A major part of the Texas A\&M code development work involved the creation of three state-of-the-ar't simulators for flow through porous media. These models can be used to successively model more complicated groundwater systems. All codes include version: developed for execution on modern parallel computing envirunments and show very effective scaleup in computations involving a large number of processors.

\subsubsection{US3D}

The (serial) simulator US3D

$$
\text { "http://www.isc.tamu.edu/JEP/zleyk/us3d.html", }
$$

solves the three-dimensional groundwater flow and contaminant transport equations with fluid density and viscosity being functions of contaminant concentration. It is based on Richards' equation, which assumes that the air pressure is constant and equal to the atmospheric pressure throughout the simulated region. This is a valid assumotion in many physical systems such as surface infiltration. 
A trilinear finite element approximation based on a mesh of distorted parallellopiped elements was developed and is employed for both flow and concentration transport. The code hendles both saturated and unsaturated flow conditions.

To develop a supportable version, the initial FORTRAN version developed by M. Celia, was rewritten in ANSI-C. This enabled the addition of new capabilities including well models, new iterative solvers, dynamic memory allocation, restart options, and diffusive flux boundary conditions. The serial version of US3D is a useful tool which provides a capability for making preliminary investigations on universally available desktop workstations. Contributions to this effort were made by researchers at Princeton, Texas A\&M, and USC.

To enable the US3D model to simulate more complicated physical systems with more complex geometry and processes, a parallel version

$$
\text { “htt,p://www.isc.tamu.edu/PICS/us3d-mp", }
$$

US3D-MP was developed. To improve scalability, the parallel version utilizes communication routines that avoid global synchronization in the domain decomposition implementation. Thus, the scalability of the code is only limited by the ratio of boundary to interior points and the cost of doing some global sums employea in the iterative solvers. The message passing was implemented in primitive NX for efficiency on Intel machines as well as MPI for portability to other platforms. Additional capabilities such as restart and better preconditioning were also incorporated. This work was done at BNL and Texas A\&M.

\subsubsection{GCT1.2}

The GCT1.2 code employs the Richards' flow model described above coupled with multicomponent transport. The transport options provide capabilities for including radionuclide: decay, as well as chemical and biological reactions between components. The code is parallelized and allows a density dependency on the distribution of the components. Coupled flow and transport equations are solved in a sequential manner by alternating flow and transport steps. Transport includes 
two options whereby the equations can be solved by either the characteristic mixed method or a hig, h order Godunov scheme. The flow code was developed at TAMU and BNL, and the transport component was developed at UT.

The combined code has be tested on a number of benchmark and application problems. The input and results of these computations can be found at the PICS code repository at ORNL. The test problems range over a wide range of complexity starting from simple model problems and progressing to complex physical applications modeling flow through complicated geological structure.

\subsubsection{GCT1.3 Two-Phase Flow Model}

The two-phase flow model used in GCT1.3,

"http://wwrv.isc.tamu.edu/JEP/tsun/pics/PicsCode.html",

is based on a total pressure formulation similar to those described in ChavantJaffre. This results in two coupled equations; one for the total pressure and the other for the water saturation. The pressure equation is parabolic while the saturation equation is more transport dominated. The pressure equation is discretized by a mixed finite element approximation on a mesh of distorted rectangular parallelepipeds. The mesh distortion makes the modeling of rather complex geological structure feasible. Each parallelepiped is partitioned into five tetrahedra and the lowest order Raviart-Thomas mixed finite element space is used for approximation. The saturation equation is approximated using a piecewise linear upwind finite element approximation with respect to the tetrahedral partitioning discussed above.

The code is built from a library of low level modules, such as solution techniques, matrix assembling, methods of discretization, general physics, input and output, and parallel communications. These modules provide a powerful tool to implement, assemble, and experiment with various physical models. This collection of independent modules is highly object-oriented; this makes it easier to modify any part of the code with little knowledge of the other parts. Users or 
programmers can choose different modules to build completely different applications. The saturation, pressure, and Lagrange multiplier codes (solution module) have been integrated iato the library.

The code includes input and output modules. Mesh files prepared by G3D can be used with little change. In addition, output created by the code is easily viewed with G3D.

GCT1.3 flow was developed by researchers at BNL, TAMU, and USC.

\subsection{Solution Techniques}

Along with the code development, the PICS effort at Texas A\&M University lead to a number of research advancements which resulted in publications in various mathematical journals. Since the two-phase simulator was based on a mixed finite element approximation, research into the effective solution of the resulting systems of equations was initiated.

Two distinct approaches were studied. The first approach involved the direct iterative solution of the saddle-point problems which result from mixed approximation. As well as applying earlier techniques from [1] and [2], new results for the inexact Uzawa iteration were developed for both symmetric and non-symmetric saddle point problems $[2,4]$. The second approach invoived the introduction of additional multipliers and degrees of freedom on the faces of the tetrahedron. It is then possible to eliminate the pressure and velocity unknowns leaving a symmetric and positive definite system involving only the newly introduced multipliers. This system was studied and preconditioning techniques for its efficient solution were developed $[11,22,24]$. A two level scheme was used to reduce the preconditioning problem to a difference operator with a seven point stencil. The results also extend to the anisotropic case.

In addition to the development of the global iterative strategy, there are other issues arising from the necessity of developing efficient parallel algorithms. To minimize inter-processor communication and storage requirements, preconditioners based on non-overlapping techniques were studied. In particular, a new non- 
overlapping technique which allowed the replacement of exact subdomain solves by preconditioners was developed in [3]. Techniques for developing effective subdomain preconditioners (or inexact solves) were also given in [1]. Multigrid preconditioners were presented in $[10,8]$.

In a series of papers $[32,33,34,35]$ we have developed an approximation strategy for convection and convection-diffusion problem based on the finite volume method. The main advantage of this approach is conservation of the mass locally over the finite volumes. This approach has been studied in two practically significant cases: (1) general grids in $[34,35]$ and (2) structured grids with local parch refinement in [32,33]. In both cases optimal with respect to the regularity error estimates have been derived. Also superconvergence results related to more accurate velocity recovery have been obtained.

Techniques for reactive flow and transport $[10,7,15]$ and multiphase and compositional flows were present in $[13,36,17,18,19,7,5,9,29]$. Upscaling results were described. in $[14,26,20]$. Eulerian Lagrangian were presented in $[40,37]$.

\subsection{Parameter Estimation}

Work in the area of parameter estimation

$$
\text { "http://wuw.isc.tamu.edu/PICS/ParameterEstimation/", }
$$

for groundwater flow in porous media centered on two areas: investigating mathematical methods for recovering multi-scale permeabilities using weighted least squares techniques, and multiphase (three-phase) flow modeling using core samples.

The first area of research was carried out under the direction of Prof. Michael S. Pilant, Department of Mathematics, Aerospace Engineering. and Computer Science, along with and several students. The major results are the development of a least squares algorithm which incorporates multi-resolution analysis (wavelet basis functions) to capture the multi-scale features of the unknown permeabilities. 
The second area was carried out under the direction of Prof. A. Ted Watson, Dept. of Chemical Exgineering, Texas A\&M University and Direction of the Engineering Imaging Laboratory,

"http://www-chen.tamu.edu/CHEN/faculty/watson/hello.htm", and "http://www-chen.tamu.edu/EIL/".

\subsection{References}

1. J.E. Pasciak anc. J.H. Bramble, A preconditioning technique for indefinite systems resulting from mixed approximations of elliptic problems, Math. Comp., 50 (1988), 1-18.

2. T. Rusten and R. Winther, A preconditioned iterative method for saddle point problems, SIAM J. Matrix Anal. Appl., 13, (1992), 887-904.

\subsection{Publications Resulting from DOE Grant DE-FG03-95ER25263}

1. J.H. Bramble, R.E. Ewing, J.E. Pasciak, and J. Shen, The analysis of multigrid algorithms for cell centered finite difference methods, Advances in Computational Maíh., 5 (1996), 15-29.

2. J.H. Bramble, J.E. Pasciak, and A. Vassilev, Analysis of the inexact Uzawa algorithm for såddle point problems, SIAM J. Numer. Anal., 34 (1997), 1072-1092.

3. J.H. Bramble, I.E. Pasciak, and A. Vassilev, Analysis of non-overlapping domain decomposition algorithms with inexact solves, Math. Comp., 66 (1997), 179-196.

4. J.H. Bramble, J.E. Pasciak, and A. Vassilev, Inexact Uzawa algorithms for nonsymmetric saddle point problems, ISC Texas ABM University, Technical Report ISC-97-06-MATH.

5. Z. Chen and R.J. Ewing, Comparison of various formulations of three-phase flow in porous media, J. Comp. Phys., 132 (1997), 362-373. 
6. Z. Chen and R.E. Ewing, Domain decomposition methods and multilevel preconditioners for nonconforming and mixed methods for partial differential problems, Domain Decomposition Methods in Sciences and Engineering (R. Glowinski, ef; al., eds.), Wiley-Interscience-Europe, 1997, 213-220.

7. Z. Chen and R.E. Ewing, Fully discrete finite element analysis of multiphase flow in groundwater hydrology, SIAM J. Numer. Anal, 34(6) (1997), 2228-2253.

8. Z. Chen and R.F. Ewing, Recent development of multigrid algorithms for mixed and nonconforming methods for second order elliptic problems, Proceedings of $7^{\text {th }}$ Copper Mountain Conference on Multigrid Methods, (N. Nelson, et.al. eds.) NASA Conference Publications 33 39, 1 (1996), 183197.

9. Z. Chen and R.Ei. Ewing, From single-phase to compositional flow: applicability of mixed funite elements (with Z. Chen), Transport in Porous Media, 27 (1997), 225-?242.

10. Z. Chen and R.E. Ewing, Stability and convergence of a finite element method for reactive transport in groundwater, SIAM J. Numer. Anal., 34 (1997), 881-904

11. Z. Chen, R.E. Ewing, R. Lazarov, S. Maliassov, and Y. Kuznetsov, Mulilevel preconditioners for mixed methods for second order elliptic problems, Numer. Lin. Aig. with Appl., 3(5) (1996), 427-453.

12. Z. Chen, R.E. Eiwing, Y. Kuznetsov, Lazarov, S. Maliassov, Multilevel preconditioners for mixed methods for second order elliptic problems, Numer. Lin. Alg. with .Appl., 3(5) (1996), 427-453.

13. R.E. Ewing, Aspects of numerical methods in multiphase flows, Subsurface Flow and Transport: A Stochastic Approach (eds. Gedeon Dagan and Sholomo P. Neuman), Cambridge University Press, 1997, 92-100.

14. R.E. Ewing, Aspects of upscaling in simulation of flow in porous media, Advances in Water Resources, 20(5-6) (1997), 349-358. 
15. R.E. Ewing, Computational sciences in environmental applications, Computational Science for the $21^{\text {th }}$ Century, John Wiley \& Sons, (J. Periaux et. al. eds.) Ltd., Sussex, England, 1997, 250-259.

16. R.E. Ewing, Mathematical modeling and simulation for applications of fluid flow in porous media, Current and Future Directions in Applied Mathematics (M. Alber, B. Hu, J. Rosenthal, eds.), Birkhauser, Berlin, Germany, 1997, 161-182.

17. R.E. Ewing, Multidisciplinary interactions in energy and environmental modeling, J. Comp. Appl. Math., 74(1-2) (1996), 193-215.

18. R.E. Ewing, The need for multidisciplinary involvement in groundwater contaminant simulations, Proceedings of Next Generation Environmental Models and Computational Methods (G. Delic and M. Wheeler, eds.), SIAM, Philadelphia, PA, 1997, 227-245.

19. R.E. Ewing, Nunerical simulation of the multiphase flow of contaminants in porous media, Modeling and Computation in Environmental Sciences, $(R$. Helmig, W. Jágır, W. Kingilbadn, P. Knabner, G. Wittum, eds.) Notes on Numerical Fluia Mechanics, Verlag Viewig, Wiesbaden, 59 (1997), 133-145.

20. R.E. Ewing, Upscaling issues in parameter estiamtion of models for flow in porous media, Proceedings fo the Conference of Inverse Problem, Contral, and Shape Optinization, Carthage, Tunisia, April8-10, 1998 (to appear).

21. R.E. Ewing, A.J. Kurdila, and M. Pilant, "Multiresolution Analysis of Partial Differential Equations on Irregular Domains," Proceedings of the Society of Engineering Science 31st Annual Technical Meeting, Texas A\&M University, College Station, Texas, October 10-12, 1994.

22. R.E. Ewing, Yu. Kuznetsov, R.D. Lazarov, and S. Maliassov, Preconditioning of nonconforming finite element approximations of second order elliptic equations, Advances in Numerical Methods and Applications $O\left(h^{3}\right)$ (I.T. Dimov, Bl. Sendov, and P.S. Vassilevski, eds.), World Scientific, Singapore, 1994, 101-110. 
23. R.E. Ewing, R.D. Lazarov, J.E. Pasciak, and A.T. Vassilev, Mathematical modeling, numerical technique, and computer simulation of flow and transport in porcus media, ISC Texas A\&M University, Technical Report ISC-95-03-MATH, Proceedings of Computational Techniques and Applications CTAC 95, World Scientific, (1996), 13-30.

24. R.E. Ewing, S. Maliassov, Preconditioning techniques for mixed and nonconforming finite element methods, Proceedings Conf. Algebraic Multilevel Iteration Methods with Applications, Vol. I (O. Axelsson, B. Polman, eds.), University of Nijmegen, Nijmegen, The Netherlands, 1996, 7-22.

25. R.E. Ewing, S.D. Margenov and P.S. Vassilevski, Preconditioning the biharmonic equation by multilevel iterations, Mathematika Balkanica, 10 (1996), 121-132.

26. R.E. Ewing, Y.F. Lin, and J.P. Wang, A numerical approximation of nonFickian flows with mixing length growth in porous media, Proceedings of the Third Workshop on Computational Method for Oceanic, Atmospheric, and Groundwater Flows, Rio de Janeiro, Brazil, 1997 (to appear).

27. R.E. Ewing, M.S. Pilant, J.G. Wade, and A.T. Watson Estimating parameters in scientific computation: A survey of experience from oil and groundwater modeling, IEEE Computational Science S Engineering, 1(3) (1994), 19-31.

28. R.E. Ewing, M.S. Pilant, J.G. Wade, and A.T. Watson, Identification and control problems in petroleum and groundwater modeling, Control Problems in Industry (I. Lasiecka and B. Morton, eds.), Progress in Systems and Control Theory, Birkhaüser, San Diego, California, 21 (1995), 119-149.

29. R.E. Ewing, J.P. Wang, and S. Weekes, On the simulation of multicomponent gas flow in porous media, Proceedings II. Pan American Workshop on Applied and Computational Mathematics, Granada, Brazil, 1997, (to appear).

30. L.S. Johnson, A. Kaulgud, R.C. Sharpley, R.E. Ewing, Z. Leyk, J. Pasicak, M.A. Celia, anc. J.R. Brannan, Integration of contaminant transport simu- 
lators on parallel machines wih a graphical user interface for remote interactive modeling, Proceedings of the High Performance Computing Symposium on Porous Media Applications (Adrian Tentner eds.), (1997), 319-324.

31. J. Ko, A.J. Kurdila, and M. Pilant, "Triangular Wavelet-Basaed Finite EIements via Multivalued Scaling Functions," Proceedings of the 36th Structures, Structural Dynamics, and Materials Conference, New Orleans, LA, April 10-13, 1995.

32. R. Lazarov, I. Mishev and P. Vassilevski, Finite volume approximation of convection-diffusion problems on grids with local refinement, Computing, 53 (1), (1994), 33-57.

33. R. Lazarov, I. Mishev and P. Vassilevski, Finite volume methods for convectiondiffusion problenıs, SIAM J. Numer. Anal., 33(1), (1996), 31-55.

34. R. Lazarov and I. Mishev, Finite volume method for reaction-diffusion problems, Proc. First Intern. Symposium on Finite Volume Methods for Complex Applications (F. Benkhaldoun and R. Vilsmeier, Eds.), July 15 - 18, 1996, Rouen, France, 233-240.

35. I. Mishev, Finite volume methods on Voronoi meshes, Technical Report ISC-96-09-MATH, 1996, (submitted to Numer. Methods for PDEs).

30. G. Qin, H. Wang, R.E. Ewing, and M. Espedal, Efficiert numerical solution techniques for compositional models, IMACS Series in Computational and Applied Mathematics, Vol. 3, Iterative Methods in Linear Algebra II (S. Margenov and P. Vassilevski, eds.), Int. Ass. for Math. and Comp. in Simulation, Piscataway, New Jersey, 1996, 427-439.

37. G. Qin, H. Wang, R.E. Ewing, M. Espedal, and R.C. Sharpley, Development of an ELLAM simulator for compositional fluid flow, and R.C. Sharpley), Comp. Meth. Appl. Mech. Eng., (to appear).

38. M. S. Pilant, "Parameter Estimation Issues for Flow in Porous Media", Proceedings of the 1995 NGEMCOM conference, EPA Supercomputing Facility, Bay City, Michigan, August, 1995. 
39. M. S. Pilant, "Triangular Wavelet-Based Finite Elements via Multivalued Scaling Equationis," Computer Methods in Applied Mechanics, to appear.

40. H. Wang, R.E. Ewing, G. Qin, S. Lyons, and S. Man, An ELLAM scheme for advection-dispersion equations in two dimensions, SIAM J. of Sci. Computing, (to appear).

\section{State University of New York at Stony Brook}

The contributions to the PICS grand challenge effort from SUNY - Stony Brook are in three areas: (1) the development of two and three dimensional front tracking code; (2) field applications of the GCT code; and (3) the development of parameter estimation tools and related theoretical and numerical study of the scale up problem for flow in porous media.

\subsection{Code Development}

A complete version of the front tracking code, named FronTier, is now available for beta release. Complete information on the FronTier code, including obtaining, compiling and running; a version, can be found on the FronTier homepage

\section{"http://www.ams.sunysb.edu/shock/FTdoc/FTmain.html".}

FronTier is intended as a modeling tool for general hydrodynamic computations and it will support both 2- and 3-dimensional hyperbolic transport computations. It supports perrallel computation and has been run on a variety of parallel platforms including the Intel Paragon, which was the target design architecture of this grand challenge effort. The two dimensional code has undergone extensive testing for a large variety of problems including two phase flow in porous media, gas-dynamics, accelerated two-fluid mixing, and elastic-plastic materials $[4,6,7,8]$. The three dimensional code has been tested on computations including two phase flow in porous media, gas-dynamics and accelerated two-fluid mixing [3]. Current algorithmic development is related to handling topological 
change of surface interfaces in three dimensions either through bifurcation of a single front or the interaction of distinct fronts. Automatic resolution of such changing topology is being developed.

\subsection{Field Applications}

A preliminary single phase flow model for the Peconic River watershed region on Long Island was developed for the GCT-1.2 code. However the tritium and ethylene dibromide (EDB) contaminant plumes at Brookhaven National Laboratory (BNL) became public knowledge simultaneously with the watershed work. Consequently we diverted our field application work to model contaminant flow on the BNL site. This modeling was done in conjunction with our BNL collaborators in the PICS consortiun and the BNL office of Environmental Restoration.

The first study [1] concentrated on the site known as Operable Unit Number 1. This site had been modeled by two environmental consulting companies, CDM, Inc. and Geraghty and Miller. This provided an opportunity to test the GCT 1.2 on a site that had been previously modeled with other numerical models. Thus this first study was intended to be a cross-validation test for the GCT 1.2 code. The hydrogeological daia was adapted from the CDM model and results compared with the other two models. Since none of the models were capable of including radio-nuclide chemistry, all the models followed the transport of a conservative contamirant from fixed buried sources corresponding to the former and current landfills and the Hazardous Waste Management Facility (HWMF) within the site. Emphasis was placed on estimating how much uncertainty is incorporated in low resolution models (in the vertical direction) by simulating the site with differen; numbers of vertical layers. Consequently three different grid models were built, consisting of 8-, 12- and 20- vertical layers covering the three major geological units of the site (Upper Glacial and Magothy aquifers, and the Gardiners clay belt). Flow field calculations from the three numerical models, DYNFLOW/DYNTRACK (CDM), MODFLOW/MODPATH (Geraghty $\&$ Miller) and the GCT code were almost identical, with small variations due 
to different grid configurations. All three transport codes predicted the same southward direction of plume movement. The 20 layer GCT model produced more vertical resolution than the commercial simulations. The 20 layer GCT model indicated a division of the contaminant plume into upper and lower zones. This division is due to the stratigraphic separation of the contaminant sources in the landfills and HWMF. This vertical plume separation was not apparent in the less vertically-resolved 8- snd 12- layer GCT models and the DYNFLOW/TRACK, MODFLOW/TRACK models.

The second study modeled an ethylene dibromide (EDB) plume. In the 1960's and 1970's, EDB was used to sterilize soil as part of agricultural experiments done in an area known as the Biology Fields. Remnants of the EDB treatment have entered the groundwater in the Upper Glacial aquifer, traveled south of the Fields to the BN], boundary, and is now threatening to impact the water quality of several residential areas. Our study concentrated on evaluating the importance of small-scale heterogeneities on the plume movement. The Gardiners Clay unit separating the Upper Glacial and Magothy aquifer units underlying Long Island is known not to be continuous. Additionally, the Upper Glacial aquifer is known to contain clay lenses. Three studies were done [2], the first containing no small-scale heterogeneities was used for comparison purposes, the second placed clay lenses in the Upper Glacial aquifer directly in front of the advancing EDB plume, while the third assumed a hole in the Gardiners Clay unit resulting in direct connection between the the Upper Glacial and Magothy units directly underneath the region of highest plume concentration. The addition of clay lenses in the Glacial Unit created additional transverse dispersion in the plume shape but did not significantly alter the rate of southward advance of the overall plume. In the simulation with the hole in the Gardiners Clay, EDB migrated into the Magothy rather than remaining confined to the Upper Glacial with the additional result that the overall southward migration of the plume was slowed. The simulation results were displayed using the South Carolina graphics package G3D. As G3D supports the input of additional 'texture maps', we were 
able to overlay ARC/INFO maps of site characteristics on top of the simulation results. This proved a powerful visualization tool.

\subsection{Parameter Estimation}

A stochastic parameter estimation package, PEST, is available to provide realizations of stochastic scalar fields with desired covariance function properties. Currently the code, documentation and test data can be obtained by sending e-mail towoh@ams.sunysb.edu. It will soon be available from the web site

\section{"http://www.ams.sunysb.edu/lindquis/pics.html".}

PEST will generate unconditioned 2- and 3D realizations of a scalar field having one of several covariance or semivariogram forms. Using a convolution integral (and FFT's), stationary, isotropic, Gaussian fields with covariance

$$
C(r)=a r^{\beta}, \quad \beta \in(-\infty, 0)
$$

can be generated. Using either the method of successive random addition or the random Weierstrass-Mandelbrot function, fields with covariance

$$
C(r)=a r^{\beta}, \quad \beta \in(0,2)
$$

can be generated. Stationary Gaussian fields with power-law variogram (stationary increment behavior) can be generated using the method of Turning Bands. The Turning Band method can also be used to generate fields with an exponential covariance structure. Finally the LU decomposition method can be used to generate 1-, 2- of 3D realizations of exponential covariance. However this method is very memory intensive and is used primarily to develop $1 \mathrm{D}$ realizations which are then utilized by the Turning Band method to generate 2- and 3D fields of exponential covariance.

PEST also provides the capability of conditioning any of these realizations to data measured at given spatial locations. The resultant realization thus has 
global stochastic variation with the required covariance/semi-variogram behavior, combined with local agreement to measured data.

This package has been applied to a large (37,483 locations) set of conductivity data from the Savannah River site. The spatial two point covariance function was estimated from this daija set up to a lag of 250 feet. As information on layering of the site was unavailable in the data, any covariance due to layers is included within this single covariance estimate. Stochastic realizations of a three dimensional conductivity field having this two point covariance structure were generated for the entire site using the Turning Band method. These realizations were then conditioned point-wise to the given data, resulting in conductivity fields for the entire site that provided interpolation values between measured locations that were consistent the covariance structure determined by the measured data. The stochastic nature of the realizations is ultimately necessary in order to establish bounds on predicted flow behaviors.

The code was also used to provide unconditioned stochastic realizations with exponential covariance structure to PICS collaborators at U.T. Austin.

Scale-up refers to any method which represents the fine scale geological heterogeneity in an effective or equivalent coarse grid description for the purpose of fluid flow simulations. This problem is of great importance, as it will allow more rapid simulations, by factors of up to $10^{4}$, when the space-time grid is coarsened by a linear factor of 10 . On the basis of this increased speed of simulation, examination of a broader range of geological variation will be allowed, so that the inherently stochastic nature of the flow prediction problem can be addressed at a quantitative, mathematical level. Theoretical and numerical work has been devoted to the stochastic analysis of the flow, based on statistical assumptions concerning the geology. Past work has examined linear (miscible) displacement processes, as is typical of contaminants at low concentration in environmental remediation problems. Here, the stochastic solution typically results in anomalous (i.e. non-Fickean) diffusion, with a longitudinal diffusion constant depending on travel distance. ' This is due to the increased length scales of heterogeneity 
observed by the flow as its travel distance increases. During the past year we have shown [8] that ra-normalization of nonlinear (immiscible) flow typical of petroleum reservoir management, requires a re-normalization of the hyperbolic terms (fractional flow function and relative permeabilities) rather than the dispersive terms in the flow equations. Key variables identified as influencing the re-normalization included the mobility ratio, and the length scales, strength, and anisotropy of the geolcogical heterogeneity.

\subsection{Publications Resulting from DOE Grant DE-FG02-95ER25265}

1. P. Dziedzic, Model of contaminant transport in groundwater at Brookhaven National Laboratory, Long Island, New York. Master thesis, Dept. of Geosciences, State University of New York at Stony Brook, Aug. 1996.

2. A. C. Bennett, Modeling the effects of stratigraphic heterogeneities on contaminant transport in groundwater. Master thesis, Dept. of Geosciences, State University of New York at Stony Brook, May 1997.

3. J. Glimm, J. W. Grove, X.-L. Li and K.-M. Shyue, Three Dimensional Front Tracking. SIAM J. Sci. Comp., 19 (1998), (to appear).

4. J. Glimm, M. J. Graham, J. Grove, X.-L. Li, T. M. Smith, D. Tan, F. Tangerman, and Q. Zhang, Front Tracking in Two and Three Dimensions, J. Comp. Math. To Appear.

5. J. Glimm, J. Grove, X. L. Li, and D. C. Tan, Robust Computational Algorithms for Dynamic Interface Tracking in Three Dimensions. In Preparation.

6. Y. Song, W. Chui, J. Glimm, B. Lindquist, and F.M. Tangerman, Applications of Front Tracking to the Simulation of Resin Transfer Modeling, Computers 8 Mathematics with Applications, (1997), (to appear).

7. J. Glimm, S.R. Simanca, D. Tan, F.M. Tangerman, and G. Van Der Woude, Front Tracking Simulations of Ion Deposition and Resputtering, submitted to SIAM J. Sci. Comput.. 
8. J. Glimm, H. Kirn, D. Sharp, and T. Wallstrom, A Stochastic Analysis of the Scale Up Prcblem for Flow in Porous Media. Comput. Appl. Math., 17, (to appear).

\section{University of South Carolina}

The University of South Carolina contributed primarily in five areas to the PICS project: (i) ELLAM algorithm development for advection-diffusion-reaction equations, (ii) development and testing of data compression algorithms to enable interactive simulations over standard bandwidth networks, (iii) development of graphical user interfaces for preprocessing input data, model development, and post-processing simulations for analysis, (iv) development of an general purpose library for remote interactive tracking and steering of simulations on massively parallel machines, and (v) collaboration with the Savannah River Site in providing realistic field site data as test cases for the PICS simulators. More details on the University of South Carolina's PICS contributions and activities are available at "http://www.math.sc.edu/ sharpley/pics.html".

\subsection{Numerical Algorithms for Advection-Diffusion-Reaction Equations - ELLAM}

The sensitive numerics of advection-diffusion equations, appearing both in the saturation equation of the flow code and in the transport equations, require careful treatment in order to efficiently achieve the accuracy required for these coupled model equations. South Carolina continued its collaboration with Princeton and Texas A\&M on Eulerian-Lagrangian Localized Adjoint Methods (ELLAM) for the numerical solution of advection-dominated partial differential equations. Significant results have been obtained on the convergence analysis of ELLAM schemes [10,11], development of algorithms for advection-diffusion-reaction equations $[9,10,11,12,13]$, domain decomposition and space-time local refinements $[11,13]$, and the numerical simulation of compositional models [9]. 
Many numerical methods for the solution of one- and two-dimensional advectiondiffusion-reaction partial differential equations, including ELLAM schemes, Galerkin finite element methods, quadratic Petrov-Galerkin methods, cubic Petrov-Galerkin methods, streamline diffusion methods, Flux Corrected Transport, and Godunov schemes, have been systematically compared under a variety of initial and boundary conditions. The result of these comparisons have demonstrated the strong potential of ELLAM schemes to address the model transport equations.

\subsection{Input Modules for GCT 1.3}

South Carolina, in collaboration with Princeton, Savannah River, and Texas A\&M provided bounciary condition specifications. The primary input modules were developed by Mohammed Al-Lawatia and have been delivered to satisfy the corresponding part of the milestones. Complete documentation and examples were included. The modules were merged into the official GCT 1.3 code and conform to the new input standards. This effort was coordinated with Pasciak (BNL/TAMU), Vassilev (TAMU), Celia (Princeton), and the G3D development team. Thorough testing has been completed for each of the primary WEB moduies (grid, initial conditions, boundary conditions, and material properties). Special data structures were designed and implemented for the efficient building, handling and storage of time-dependent boundary condition data sets.

\subsection{Graphical User Interfaces for Model Development and Analysis}

A comprehensive suite of graphical pre- and post-processors has been developed to assist practitioners with model formulation and development. These GUI's allow for easy input of all necessary parameters and system properties, and for meaningful graphical display of output from the numerical simulations. The current version of these interfaces, referred to as $\mathbf{G 3 D}([6])$,

"http://www.math.sc.edu/ sharpley/PICS/USC_PICS_4b.html", 
has been developed through funding from DOE with matching funds from the University of South Carolina. G3D currently provides a fully functional pre- and post-processing graphical interface that allows the user to easily generate and modify the numerical grid, to input and modify soil and rock properties, and to impose appropriate initial and boundary conditions. It provides a data synthesis capability which facilitates detection of user input errors as well as providing an efficient methodology for refinement of the modeling process. G3D provides animated graphical display of evolving contaminant plumes in three-dimensions, with options to plot iso-concentration surfaces or color shadings with varying degrees of opacity.

Additional G3D tools include 3-D mouse view control, multiple views, VCR record and playback, overlay and stereo imaging, grid and model editing, including full boundary condition GUI editing for time-dependent boundary conditions of all types. Multiple scalar and vector data are simultaneously processed, as well as the simultaneous rendering of soil and fluid features. Additional images, model animations, and source codes are available from the WEB site printed above, and the URL “http://www.math.sc.edu/“sharpley/PICS/USC_PICS_4a.html\#movie".

In order to provide for efficient and effective use of both the GUI's and the parallel simulators on cemote massively parallel machines, we have also developed a general purpose Controller Library which is described in more detail in the next subsection.

\subsection{Tracking/Steering Library}

An Interactive Tracking/Steering Library with the parallel machine (e.g., Paragon) as server and UNIX workstations (e.g. Silicon Graphics) as clients has been developed and may be obtained from the ORNL repository or from South Carolina's ftp site. This is a general purpose library which was developed for interactive remote tracking and steering of simulations and which conforms to specifications as set by GCT code developer J. Pasciak (BNL). The library has been tested on the satellite PICS Paragons, as well as the main production machines 
at ORNL, to ensure compatibility of the remote procedure calls with security at each site. Components delivered include: (i) client and server libraries, (ii) Steering/Tracking inst!umented versions of GCT1.2 and US3D ([5]) for interactive remote use with the G3D graphical interface, (iii) four additional working example codes in increasing order of complexity, (iv) TeX user documentation, (v) FAQ (Frequently asked questions), 'Man' pages for on-line help. Additional information and a user manual is available online at the URL

$$
\text { “http://www.math.sc.edu/ sharpley/Steer.html". }
$$

The library permits remote tracking and steering of simulations on supercomputers from local workstations with user-determined levels of interruption to maintain load-balance synchronization, and integrity of data to be transferred. This library has been ported to the MPI message passing language, has been coupled with G3D, specialized data compression modules, and three of the PICS groundwater contaminant codes $[5,8]$ to provide interactive groundwater simulations on remote Parı́gons.

\subsection{Data Compression}

Extensive testing and usage of network connections to PICS machines at ORNL and member institutions, provided convincing evidence that the use of compatible data compression tools will be necessary for hydrologists and field engineers to perform interactive Grand Challenge simulations from their local workstations.

South Carolina has; developed algorithms ([4]) for both client and server compression modules to address this problem and are tuning them for groundwater applications. During this grant period, we have developed and implemented 3D algorithms (both single and multiple processor versions on the server machine, i.e. Paragon) designed to je coupled with the user interface codes and compress data as it is generated by (GCT applications in a non-interruptive manner. The algorithms and research codes use nonlinear approximation and specialized entropy encoders, which have proven to be extremely successful for wavelet compression 
of $2 \mathrm{D}$ images applied to hyperbolic wavelet bases. We have developed $3 \mathrm{D}$ variants of Shapiro's method fol: comparison and have tested these implementations with our Steering library coupling US3D with our G3D graphical user interface.

These compression algorithms applied to the both smooth (e.g., pressures) and to rough fields (transport solutions generated by the highly heterogeneous Old Burial Ground dal;a at SRS) have achieved impressive rates of compression without discernible losis of visual information, and provides up to 1,200 times compression with excellent visual retention of qualitative features "http://www.math.sc.edu/ sharpley/PICS/USC_PICS_4b.html\#4b3".

\subsection{Field Application Simulations}

Data was provided in several forms by our collaborators in the Environmental Sciences Division of the Savannah River Technology Center “http://www.math.sc.edu/ sharpley/PICS/USC_PICS_4c.html”.

Project personnel James Brannan of Clemson University worked closely with Luther Hamm and Gregory Flach of SRS to assist in developing the theory, algorithms and softwere tools for processing raw data into input files for both HPC codes. The goal is to create software which incorporates scale-up techniques, data fusion methods, and permits input of soft or subjective geological knowledge. These issues will be ccitical for providing practicing hydrologists access to HPC simulators developed through the PICS project.

The SRS raw datí was assimilated and used for flow and transport simulations on $128 \times 128 \times 64$ model runs, as well as several smaller model versions. Qualitative feedback of the model runs by SRS collaborators has resulted in a detailed flow field of the site. The model data were also critical in debugging several components of the GCT codes and illustrated the need for distributed I/O for model data in this application field. QuickTime and MPEG animations of the simulations were produced by applying $G 3 D$ to the output of these models for both flow 
"http://www.math.sc.edu/ sharpley/PICS/USC_PICS_4a.html\#movie2".

and transport

"http://www.math.sc.edu/ sharpley/PICS/USC_PICS_4a.html\#movie".

The original flow runs were performed on the XPS150 at ORNL by South Carolina personnel and the results were demonstrated at the ORNL booth during SuperComputing' 95. 


\subsection{Publications Resulting from DOE Grant DE-FG05-95ER25266}

1. R.J. Babarsky and R.C. Sharpley, Expanded stability through higher temporal accuracy fcr time-centered advection schemes. Monthly Weather Review, 125(June 1997), 1277-1295.

2. K. J. Bene, E. K. Paleologos, M. M. Meadows, Geostatistical Analyses of Laboratory and In-situ Measurements of Saturated Hydraulic Conductivity, Abstracts of the 46th Annual Southeastern Section of the Geological Society of America, 29(3)(March 1997), 4.

3. K. J. Bene, R. P. Ray, M.M. Meadows, E. K. Paleologos, Application of Geostatistics to Site Characterization, Annales Geophysicae, European Geophysical Society (1997), 266.

4. Z. Gao, A. Andreev and R.C. Sharpley, Elementary Encoding of Wavelet Coefficients, IMI Report 97:02, Department of Mathematics, University of South Carolina, Columbia, SC (Jan. 97).

5. L.S. Johnson, A. Kaulgud, R.C. Sharpley, R.E. Ewing, Z. Leyk, J. Pasciak, M. Celia, and J.R. Brannan, Integration of Contaminant Transport Simulators on Parallel Machines with a Graphical User Interface for Remote Interactive Modiling, in "Proceedings of the 1997 Simulacion Multiconference," Atlanta, April 1997, Soc. for Computer Simulation International, San Diego.

6. L.S. Johnson, A. Kaulgud and R.C. Sharpley, G3D: A 3D User Environment for Partial Differential Equations, IMI Report 97:01, Department of Mathematics, University of South Carolina, Columbia, SC (Jan. 97).

7. A. Kaulgud and R.C. Sharpley. An Interactive Tracking/Steering Library, IMI Report 95:10, Department of Mathematics, University of South Carolina, Columbia, SC (Aug. 1995, rev. July 1997).

8. G. Mahinthakumar, R.C. Sharpley, A. Kaulgud, and L.S. Johnson, Groundwater remediation experiments using interactive computational steering on the Intel Paragon, Intel Supercomputer Users Group Annual Conference (ISUG97), Albrquerque, NM, June 11-13, 1997. 
9. G. Qin, H. Wang;, M.S. Espedal, R.E. Ewing, and R.C. Sharpley, Development of an ELLAM simulator for compositional fluid flows, (submitted).

10. H. Wang, M. Al-Lawatia, and S.A. Telyakovskiy, A Runge-Kutta characteristic method for frst-order linear hyperbolic equations, Numerical Methods for PDEs, 13 (1997), 617-661.

11. H. Wang, M. Al-Lawatia, and R.C.Sharpley, A characteristic domain decomposition and space-time local refinement method for first-order linear hyperbolic equalions with interfaces, submitted.

12. H. Wang, H.K. Dahle, R.E. Ewing, M.S. Espedal, R.C. Sharpley, and S. Man, An Eulerian-Lagrangian localized adjoint method for advectiondispersion equations in two dimensions and its comparison to other schemes, SIAM J. Scientific Computing, (to appear).

13. H. Wang and B-G Ersland, A characteristic domain decomposition technique for two-phase flows with interfaces, accepted for publication in Proceedings of the Ninth International Conference on Domain Decomposition Methods, Ullensvang, Norway, June, 1996.

\section{Brockhaven National Laboratory}

The Brookhaven component of the project involved code development and management, field studies, and the user interface. In each of these areas BNL worked in collaboration with other institutions who had the primary role. Detailed descriptions of the work are given in the reported work from these institutions.

\subsection{Code Development}

The computational flow module effort at Brookhaven was closely coupled to work at TAMU and USC in developing a series of progressively more sophisticated parallel groundwater flow simulators. These were:

1. US3D-MP, basid on the US3D code developed by Celia The code is based on Richards equation, handles both saturated and unsaturated flow, and 
uses a mesh of distorted parallelepiped elements.

2. GCT1.2 using esisentially the modified US3D flow code, but coupled with a multicomponent transport provided by the UT group.

3. GCT1.3 incorporating a two phase flow model based on a total pressure formulation.

Brookhaven played a jundamental role in the implementation, analytic verification, parallelization and iterative solution aspects of the flow modules.

\subsection{Code Management}

BNL was involved in the planning for the code repository at Oak Ridge to allow effective cooperation and exchange of codes under development by geographically diverse groups, introducing the use of the CVS system and its modular capability as a primary tool.

\subsection{Field Application}

The field application work was carried out in close collaboration with Stony Brook. BNL was involved in that part of the project which modeled two different contaminant plumes at the BNL site. The objective was primarily to explore the effectiveness of the GCT codes on realistic models which had been relatively well studied using current generation codes, and to explore the potential of carrying out much more detailed simulations. While the developmental nature of the codes at the time they were used precluded the results being used for quantitative conclusions abcut the particular plumes being modeled, the environmental restoration group at FiNL found the results informative in understanding the sensitivity of the conclusions to the resolution of the grids near geological boundaries.

\subsection{User Interface}

Brookhaven was involved together with the current UT group in the development of a user interface for problem specification. Based on some earlier work carried 
out by the University of Texas group, a flexible, extensible, general scheme for data input was develojed for GCT. It allows data items to be specified either explicitly as numbers, or implicitly by specifying functional forms or referencing files. Each data item may have qualifying parameters. Default values are supplied for any missing items. Values can be expressed as arithmetic expressions involving values of other data items. Arrays, such as grid coordinates, can be given as a series of (possibly overlapping) subranges. Each data specification statement can use its own arbitrary units.

A code was writter which implements this scheme, driven by a simple table to make it easy to add or modify data items, parameters, or defaults. The code parses the input data set and stores an implicit representation of the data values. To provide the data files to be read by GCT, an output module needs to be written to interpret the implicit values and present them explicitly in the order and format expected by the code. Such a module was written for generating data input files for GCT1.2

A preliminary draft of a users guide to GCT, incorporating this new data input scheme, was developed in collaboration with the University of Texas group.

\section{Oak Ridge National Laboratory}

The Oak Ridge National Laboratory's contribution to the PICS project were centered around the following areas: (i) Management and testing of the GCT suite of codes, (ii) DOLIB/DONIO library development, (iii) Investigation of parallel iterative solvers fol: groundwater flow and transport problems, (iv) Adaptive triangulation for strongly anisotropic problems, (v) Biogeochemistry applications and testing, and (vi) Other ORNL groundwater code developments. More details about ORNL's contributions and activities related to the PICS project can be found in $U R L^{1}$.

\footnotetext{
${ }^{1}$ http://www.ccs.ornl.;jov/GC/gw/gw.html
} 


\subsection{Code Management and Testing of GCT}

At ORNL we maintained developmental and archival versions of the GCT1.2 and GCT1.3 suite of codes in addition to testing and integration of these codes as deemed necessary. A comprehensive but flexible directory structure, makefiles, and test problem integration were part of the code repository design. Developers were provided access to working versions of the entire suite of codes, libraries and the test problems. A revision control software, CVS (Concurrent Versions Systems), was used to aid the code management process. GCT1.2 solves the saturated/unsaturated Richard's equation for flow and and the advection dispersion equation with radioaclive chain decay for transport. The flow module of GCT1.2 is based on Galerkin finite-elements and the transport module is based on mixed finite-elements for the dispersion component and either Godunov or method of characteristics for the advection component. GCT1.3 solves two-phase flow and multicomponent transport with biogeochemical reactions. For GCT1.3, the flow is based on a mixed pressure-saturation formulation and transport uses the same formulations as GCT1.2. Both GCT1.2 and GCT1.3 source codes and documentation can be obtained from URL ${ }^{2}$.

\subsection{DOLIB/DONIO Library Development}

We developed DOLIE [15], a shared memory emulator for distributed memory architectures and DONIO [14], a high performance parallel I/O library for distributed memory architectures. DONIO was used in the GCT suite of codes to provided significant improvements in $\mathrm{I} / \mathrm{O}$ performance over native $\mathrm{NX} \mathrm{I} / \mathrm{O}$ libraries. More details about these libraries can be found from URL ${ }^{3}$. Associated publications and source code for these libraries are also available from this web page.

\footnotetext{
${ }^{2}$ http://www.ccs.ornl.gov/GC/gw/gw.html

${ }^{3}$ http://www.epm.ornl.gov/ efdazedo/softtools.htm
} 


\subsection{Adaptive Triangulation for Strongly Anisotropic Problems}

We have analyzed an adaptive triangulation technique capable of effectively discretizing highly anisots.opic problems arising from groundwater models. Results show faster convergence and higher accuracy compared to regular discretization for the same number of unknowns [12]. More details about this work including publications are available from $\mathrm{URL}^{4}$.

\subsection{Investigation of Parallel Iterative Solvers for Groundwater Flow and Transport Problems}

We investigated parallel iterative solvers based on multigrid and Krylov subspace methods for large scale groundwater flow and transport problems. The discretization is based on the Galerkin finite element method using a logically rectangular grid structure. For the saturated groundwater flow problems we implemented multigrid and multigrid preconditioned conjugate gradient methods and show a 25 times speedup over diagonally preconditioned conjugate gradient solver for problem sizes exceeding 50 million cells [3]. Our multigrid implementations are restricted to rectangular grids but could be extended to distorted logically rectangular grids. For multicomponent transport probiems we implemented several Krylov solvers and compared their relative performance on various distributed memory platforms [1]. We demonstrated very good scalability of all the solvers up to 1024 nodes of the Intel Paragon XPS/150. More details about this work can be found from UFL ${ }^{5}$.

\subsection{Biogeochemistry Applications and Testing}

In collaboration with UT-Austin, ORNL was involved in the development, testing, and application of the biogeochemistry modules for ParSSim (described elsewhere). Transport and remediation of groundwater contaminants involve a wide

\footnotetext{
${ }^{4}$ http://www.epm.ornl.gov/ efdazedo

${ }^{5} \mathrm{http} / /$ www.ccs.ornl.gov/staff/kumar.html
} 
range of geochemical and biological reactions. To address these problems, we have developed a fully couped geochemistry and bioremediation model for groundwater transport. The model allows the user to select multiple solutes and multiple species of microorganisms to interact, as well as precipitation/dissolution, adsorption/ desorption, ion exchange, oxidation/reduction, speciation, and mass transfer between fluid phases. Both equilibrium and kinetics (mass-action or Monod type) are supported. The new model, ParSSim (for Parallel Subsurface Simulator), has been tested on several problems that illustrate the importance of handling many chemical reactions simultaneously. First we examine a simple case of degradation, comparing degradation rates with single and then with multiple reactant species. This example shows the importance of being able to account for multiple organisms; contaminants, and electron donors simultaneously. The second case examines the fate of a residual NAPL phase in a geologically heterogeneous aquifer. Non-equilibrium dissolution of the NAPL contaminates the flowing groundwater. Dissolved oxygen in the water promotes degradation of the dissolved NAPL by means of microbes assumed to be resident in the aquifer. If reducing minerals such as pyrite are present in the aquifer, they compete with the biodegradation reaction for the oxygen, and significantly different degrees and extent of contamination occur. When examining transpor ${ }^{2}$ and remediation, a general description of bio/geochemical reactions (as opposed to 'hardwired' reaction schemes) is a significant advantage.

\subsection{Other Groundwater Code Developments}

ORNL was involved in the development of the following groundwater flow and transport codes with partial support from PICS. These developments were not intended to replace cr duplicate the main code development efforts by PICS. These codes were prirnarily developed to advance research that support some of the PICS goals. For example, PFEM (described below) was used to perform some of the initial flow computations to meet the ORNL field application milestones. Another example is the use of PGREM3D (described below) to complement the 
testing of the steering and graphical libraries. Finally, these codes complement the overall PICS effor; by providing a restricted suite of codes intended for a limited set of research applications. In addition to the primary PICS codes GCT, US3D-MP, and Parsim, all of the following codes are currently being used in a number of research applications at ORNL.

\subsubsection{PFEM}

PFEM is a parallel version of the original 3DFEMWATER code [19]. PFEM solves the saturated/unsaturated flow equations using the Galerkin finite element method on unstructured grids based on hexahedral brick elements. PFEM supports a variable flux boundary condition. An unstructured domain decomposition strategy was used in the parallelization.

\subsubsection{PGREM3D}

PGREM3D (Parallel (Groundwater Transport and Remediation Codes) is a suite of massively parallel codes intended for high resolution numerical simulation of groundwater transport and remediation experiments [2]. The main feature of PGREM3D is that it can solve very large problems (in the order of 10's of millions of cells) efficiently on todays parallel supercomputers. Scalability has been demonstrated for up to 1024 processors of the Intel Paragon XPS/150. As an example, transport calctlations involving about 40 million degrees of freedom takes less than 0.5 seconds fer time step (each time step involving a full matrix solve of 40 million unknowns) to execute on 1024 parallel processors of the Intel Paragon XPS/150 [1]. In its current version, the flow module of PGREM3D solves single phase saturated systems and the transport module solves multicomponent transport with non-linear bioremediation reactions. More details about these codes are available from UR, ${ }^{6}$.

\footnotetext{
${ }^{6}$ http://www.ccs.ornl.|jov/staff/kumar.html
} 


\subsubsection{DMURF/3DMURT}

Parallel 3DMURF anc. 3DMURT are multiregion flow and transport codes intended to simulate flow' and transport through fractured media. These are parallelized and three-dimerisional versions of the original two-dimensional MURF and MURT codes [Gwo et al., 1995]. High Performance Fortran (HPF) and DOLIB were used to parallelize these codes [18]. More details about these codes including associated publications are available from $\mathrm{URL}^{7}$.

1. G. Mahinthakumar, F. Saied, and A. J. Valocchi, 1997. "Comparison of some parallel krylov solvers for large scale contaminant transport simulations", High Performance Computing 1997 (Editor: A. M. Tentner), Proceedings of the 1997 Simulation Multiconference, p. 134-139, Atlanta, GA, Apr 6-10, 1997.

2. G. Mahinthakumar, 1997. "PGREM3D: Massively Parallel Codes for Groundwater Transport and Remediation", Oak Ridge National Laboratory Technical Report (in preparation), ORNL/TM-13435.

3. G. Mahinthakumar and F. Saied, 1997. "Multigrid and Krylov Solvers for Large Scale Finite Eiement Gruundwater Flow Simulations on Distributed Memory Parallel Piatforms", Oak Ridge National Laboratory Technical Report, ORNL/TM-13441.

4. G. Mahinthakurnar and F. Saied, 1996. "Distributed Memory Implementation of Multigrid Methods for Groundwater Flow problems with Rough Coefficients", High Performance Computing 1996 (Editor: A. M. Tentner), Proceedings of the 1996 Simulation Multiconference, p. 51-57, New Orleans, LA, Apr 83-11, 1996.

5. G. Mahinthakumar, R.Sharpley, A. Kaulgud, and S. Johnson, 1997. "Groundwater remediation experiments using interactive computational steering on the Intel Paragon", Intel Supercomputer User's Group Conference, Albuquerque, NM, Jun 18-20, 1997.

\footnotetext{
${ }^{7}$ http://www.ccs.ornl.jov/staff/gwo.html
} 
6. Mahinthakumar, G., Effectiveness of Pump-and-Treat Remediation in Heterogeneous Groundwater Aquifers: A Computational Investigation using the Intel Paragcn, Proceedings of the Intel Supercomputer User Group Conference, Albuquerque, New Mexico, Jun 1995.

7. S. Painter and G. Mahinthakumar, 1997. "Prediction Uncertainty for Tracer Migration in Random Heterogeneities with Multifractal Character", Oak Ridge National Laboratory Technical Report, ORNL/TM-13443. Also submitted to Int. J. Advances in Water Resources.

8. F. Saied and G. Mahinthakumar, Efficient Parallel Multigrid Based Solvers for Large Scale Groundwater Flow Simulation, Int. J. Parallel Computing with Applications, In Press, 1997.

9. Toran, L.E., Bryant, S.L., Saunders, J.A., and Wheeler, M.F. Sr mobility under variable $\mathrm{pH}$ : Application of a coupled geochemistry and transport model. Accepted in Ground Water.

10. Toran, L, Bryant, S, Eaton, J, and Wheeler, MF, 1997. Coupled geochemistry and bioresctions for remediation modeling. Spring Meeting of the American Geophysical Union, May 20-24, Baltimore, MD. EOS, 78: S166.

11. Toran, L. 1996. Parallel computing in 3-dimensional flow and transport. Third Groundwater Modei Users Workshop, Jul 30-Aug 1, 1996, Albuquerque, NM.

12. D'Azevedo, E. F., and C. H. Romine, 1995. Coefficient Adaptive Triangulation for Strongly Anisotropic Problems, ORNL/TM-13086, November 1995.

13. D'Azevedo, E. F., and C. H. Romine, 1995. DONIO: Distributed Object Network I/O Library, Intel Supercomputer Users Group report, June 1995.

14. D'Azevedo, E. F., and C. H. Romine, 1994. DONIO: Distributed Object Network I/O Library, ORNL/TM-12743, 1994.

15. D'Azevedo, E. F., and C. H. Romine, 1994. DOLIB: Distributed Object Library, ORNL/TM-12744, 1994.

16. D'Azevedo, E. F., and C. H. Romine, 1995. DOLIB: Distributed Object 
Library, to appear in Proceedings of the 1995 SIAM Conference on Parallel Processing.

17. Mackay, D., E. F. D'Azevedo, and G. Mahinthakumar, 1997. A Study of I/O in a Parallel Finite Element Groundwater Transport Code, ORNL/TM13440, May 1997 (also accepted for publication in special I/O issue of Int. J. of Parallel Coraputing).

18. D'Azevedo E. F., and J. P. Gwo, 1997. "Parallelization of a Multiregion Flow and Transport Code Using Software Emulated Global Shared Memory and High Performance Fortran", In A. Tentner (ed.), Proc. High Performance Computing, 1997, The Society for Computer Simulation, April, 1997, Atlanta.

19. Yeh, G.T., 1987, 3DFEMWATER: A three-dimensional finite element model of water flow through saturated unsaturated media, ORNL TM-6386/ESD2904,314

\section{Princeton University}

\subsection{Princeton Accomplishments}

We have pursued four distinct but related research topic st Princeton: (1) development and implementation of a procedure to quantify risks associated with ground-water contamination from complex, multi-component mixtures; (2) development and implemeatation of a general three-dimensional contaminant transport simulator based on the Eulerian-Lagrangian Localized Adjoint Method (ELLAM); (3) a computational investigation of the fractional flow approach for infiltration problems; and (4) applications to field problems associated with the aquifer being studied in detail by the U.S. Geological Survey at Cape Cod, Massachusetts. We have also worked closely with the University of South Carolina, providing technical guidance for their field applications, providing both computer codes and technical guidance for their ELLAM developments, and providing guidance on their development of graphical interfaces. One result of that collabora- 
tion if the publication by Johnson et al. (1997). The following is an overview of accomplishments for each of the four primary topics identified above.

\subsection{Risk Assessment and Quantification for Complex Mixtures}

It has become obvious that ground-water contamination sites must be prioritized in terms of importance of the resource and severity of the contamination. Severity of the problem can be quantified through use of risk assessment procedures that combine advanced numerical simulations procedures with risk-assessment measures provided by the Environmental Protection Agency. The result is a measure of total risk, and of relative risks for each compound, as a function of both space and time. Such an algorithm allows sites to be prioritized through use of a common metric, and also allows the effectiveness of potential remediation schemes to be quantified and compared.

The model we have developed is based on a set of standard advection- diffusionreaction transport equations, with the additional features that (1) both an aqueous phase and a non-£qqueous-phase liquid (NAPL) exist within the subsurface; (2) the NAPL is composed of many components; (3) the NAPL and aqueous whases interact through kinetic mass-transfer processes that are dependent or. the composition of the NAPL phase; and (4) the state of the NAPL componenis depends on the NAPL, composition, so that some of the NAPL components can solidify and precipitate out of the mixture as the NAPL composition changes. All of these processes are included because they are necessary to describe properly the behavior of known. environmental contaminants such as coal tars and various petroleum products. The model, described in detail in Blackburn (1998) and Peters et al. (1998), combines numerical approximations with certain analytical solutions to solve the coupled set of nonlinear equations. Numerical methods are applied to solve the contaminant transport equations (one equation for each component), while the individual mass-transfer equations are linearized and solved analytically. These solutions are coupled in a nonlinear iterative solution procedure. While the solution procedure is complicated, in part because the nonlin- 
earities become more difficult when specific components begin to precipitate, the overall result is a numerical solution for aqueous-phase concentrations for each component, mass fractions within the NAPL for each component, identification of any solidified components, and calculation of phase saturations for the NAPL and water phases. These solutions are then augmented by calculations of risk associated with each component.

Risk calculations are usually performed to measure the effects of exposures over a 30-year window of time. While most estimates of risk use a given (constant) concentration applied over 30 years, we use an integrated measure of concentration over 30 years of simulation to capture the temporal evolutions of the concentrations as computed in the model. The risk associated with each component is then calculated using this integrated concentration, and exposure factors compatible with U.S. Environmental Protection Agency guidance, as outlined in Peters et al. (1996). These EPA measures include carcinogenic slope factors for each component, which are either known from prior estimates in the literature, or are estimated using compound-specific toxic equivalency factors.

We have run simulations using realistic aquifer properties (taken from the Cape Cod field site) and somewhat realistic NAPL mixtures. We have looked at up to 17 components, with the compositions based on measurements of coal tars. The results, as reported in Blackburn (1998) and discussed briefly in Peters et al. (1998), show the space-time evolution of the risk factors, with the lighter components dominating the NAPL composition at early times but their relatively high mass-transfer rates lead to dominance of heavier, and more toxic, components at later times, with scme of those components solidifying and precipitating out of solution. This leads to complex risk maps, showing the importance of spatial location, of the time-averaging window used, and of solidification effects. Details may be found in the references. 


\subsection{Development of' Three-dimensional ELLAM Algorithms}

After experiencing the expected difficulties with finite element transport simulators, we developed a fully three-dimensional Eulerian-Lagrangian Localized Adjoint Method (ELLAM) solution algorithm that can solve general transport problems. The algorithm takes advantage of our previous experience (Celia et al., 1990; Zisman and Celia, 1990; Celia, 1994; Binning, 1994; Binning and Celia, 1996a; Ewing et al., 1995) as well as the experiences of many others (Healy and Russell, 1993, 1998; Wang et al., 1997). All of those previous studies provided important input and guidance, but were restricted to either one spatial dimension or two spatial dimensions. As is evident in Binning and Celia (1996a), boundary condition implementation, and evaluation of integrals at the known time level, are the two major difficulties in the ELLAM approach. These difficulties increase as the dimensionality of the problem increases. We decided on the following approach, which is now implemented.

The ELLAM scheme uses the forward tracking approach first proposed by Healy and Russell (1993). In that approach, the integrals that arise at the known time level, and along inflow boundaries, are approximated using numerical integration. Because the solution is known at all points within the domain at the known time level, it jurns out that the only unknown is the value of the test function. Because the test function is easily defined at the unknown (new) time level, each integration point is forward-tracked to the new time level, and the value of the test function is determined. A similar approach is used along inflow boundaries. Analytic tracking is used to track each integration point. The code allows for a choice of both numerical integration schemes and of test functions. Numerical integration schemes include one-, two-, and three-point Gaussian integration; trapezoidal-rule integration; and Simpson's-rule integration, all applied

cell- by-cell . Test function choices are piecewise linear, which we recommend, and piecewise constant. The code only tracks integration points in cells that have non-zero concentraticns; in this way, we do not waste computations where there is no contribution to the right-hand-side vector. We have run a number of test 
problems to verify the code, and are now running simulations related to some of the Cape Cod field experiments. The code and some of these calculations are described in Celia and Binning (1998).

\subsection{A Computational Investigation of the Fractional Flow Formulation for Infiltration Problems}

Fractional flow formuliations for two-phase flow problems exhibit several attractive attributes for numericil simulations, including the direct application of characteristicbased methods for the saturation equation, and the elliptic form of the pressure equation. These have been exploited effectively in the petroleum industry. Because these approaches are a strong candidate for two-phase ground-water problems, we investigated the methods and compared them to a finite element solver, based on a two- pressure formulation that we had previously developed. The focus of the study wes, in large part, on the implementation of boundary conditions, because the fractional flow approach does not naturally accommodate the mix of pressure and flux conditions that occur at the land surface in most infiltration problems.

We used as a test problem an experiment that had been reported previously in the literature, and which we had solved previously with the finite element code. The fractional flow solver was written so that boundary conditions were implemented in an iterative fashion; details of the implementation are in Binning and Celia (1996b) and Binning and Celia (1997). A modified-method-ofcharacteristics approach was used to solve the saturation, with local grid refinement also used to capture the sharp infiltration front. We observed that the fractional flow solver allowed time steps that were 10 to 30 times larger than those required in the finite element solver. However, the additional iterations required for the boundary conditions, the nonlinear characteristic tracking, and overhead associated with grid refinement largely offset the computational advantage, especially at exrly times when the frontal shape changes rapidly and the number of iterations in the fractional flow solver was large. Details of the numer- 
ical approaches, and of the results, can be found in Binning and Celia (1996b) and Binning and Celia (1997).

\subsection{Field Applications}

For field application, we have focused on the Cape Cod field site, which is a field research site operated and maintained by the U.S. Geological Survey. We have looked at simulation problems involving the non-reactive tracer bromide, both with and without density dependence. The study focused on the effects of density, and the effects of dimensionality of the model (two dimensions versus three dimensions). As expected, sinking of the plume is enhanced as the dimensionality increases. The results are summarized in the paper by LeBlanc and Celia (1998). Finite element methocls required very fine grids to capture the proper dynamics. This provided some of our motivation to develop the ELLAM approach.

In addition to the simulations involving saturated-zone, miscible displacement, we also used the Cape Cod field site for hypothetical simulations of the complex-mixture NAFL dissolution and transport simulations, for which we calculated risks. This was done by placing a fixed volume of NAPL, at residual saturation, into the flow field to simulate a leak. The subsequent dissolution and transport were modelıd, and space- time measures of risk were calculated. See Blackburn (1998) for details.

Finally, we are in the process of comparing the ELLAM simulator to the standard finite element simulator for the field experiments, both with and without density effects. We are particularly interested to see how much coarser the grid can be made for the ELLAM solution with density, given that a very accurate concentration is required to calculate proper densities and the associated plume sinking. 


\subsection{Publications Resulting from DOE Grant}

Binning, P.J., Modeling Unsaturated Zone Flow and Contaminant Transport in the Air and Water Phases," PhD Thesis, Department of Civil Engineering and Operations Research, Princeton University, 1994.

Binning, P. and M.A. Celia, "A Finite Volume Eulerian-Lagrangian Localized Adjoint Method for Solution of the Multiphase Contaminant Transport Equations in Two Dimensions," Water Resources Research, 32(1), 103-114, 1996a.

Binning, P. and M.A. Celia, "Practical Application of the Fractional Flow Approach to Multiphase-flow Simulation," Proceedings XI International Conference on Computational Meshods in Water Resources, Cancun Mexico, A.Aldama et. al. (eds.), Computational Mechanics Publications, Southampton, vol 1, 401-410, 1996b.

Binning, P. and M.A. Celia, "Practical Implementation of the Fractional Flow Approach to Multiphase Flow Simulation", submitted to Advances in Water Resources, August 1997.

Blackburn, E.D., "Simulation of Dissolution and Transport of Complex- Mixture NAPL's', Masters Thesis, Department of Civil Engineering and Operations Research, Princeton University, 1998.

Celia, M.A., "Eulerian-Lagrangian Localized Adjoint Methods for Contaminant Transport Simulations," Featured Paper, Proc. X Int. Conf. Computational Methods in Water Resources, Peters et al. (Eds.), Kluwer Publ., 207-216, 1994.

Celia, M.A., T.F. Russell, I. Herrera, and R.E. Ewing, "An Eulerian- Lagrangian Localized Acljoint Method for the Advection-Diffusion Transport Equation," Advances in Water Resources, 13, 187-206, 1990.

Celia, M.A. and S. Zisman, "An Eulerian-Lagrangian Localized Adjoint Method for Reactive Transport in Groundwaters," Invited Paper, Proc. Eight Int. Conf. Comp. Meth. Water Resources, Gambolati et al. (eds.), Springer, 383-392, 1990.

Celia, M.A. and F. Binning, "Development and Application of a Three- dimensional ELLAM Simulator for Ground-water Contaminant Transport", to be submitted to Computational Geosciences, 1998. 
Ewing, R.E., H. Wang, and M.A. Celia, "An Eulerian-Lagrangian Localized Adjoint Method for Reactive Transport with Biodegradation," Numerical Methods for Partial Differeritial Equations, 11, 229-254, 1995.

Healy, R.W. and T.F. Russell, "A Finite-Volume Eulerian-Lagrangian Localized Adjoint Method for Solution of the Advection-Diffusion Equation", Water Resources Research, 29, 399-413, 1993.

Healy, R.W. and T.F. Russell, "Solution of the Advection-Diffusion Equation in Two Dimensions by a Finite-Volume Eulerian-Lagrangian Localized Adjoint Method", Advances in Water Resources, 21(1), 11-26, 1998.

Johnson, L.S., A. Kaaulgud, R.C. Sharpley, M.A. Celia, R.E. Ewing, Z. Leyk, J. Pasciak, and J.R. Brannan, "Integration of Contaminant Transport Simulators on Parallel Machines with a Graphical User Interface for Remote Interactive Modeling", in High Performance Computing 1997: Grand Challenges in Computer Simulation, A. Jentner (ed.), 319-324, 1997.

LeBlanc, D.R. and M.A. Celia, "Simulation of Density Sinking in the Cape Cod Tracer Tests", to be submitted to Ground Water, 1998.

Peters, C.A., P.A. Labieniec, and C.D. Knightes, "Multicomponent NAPL Composition Dynamics and Risk", Proc. ASCE Annual Convention: Non- Aqueous Phase Liquids (NAPLs) in the Subsurface Environment: Assessment and Remediation, L.N. Reddi (ed.), 681-692, 1996.

Peters, C.A., E.D. Blackburn, and M.A. Celia, "Spatial and Temporal Variation of Composition in Multicomponent NAPLs", to appear, Proc. 11th Int. Conf. Comp. Meth. in Water Res., 1998.

Wang, H., H.K. Lahle, R.E. Ewing, M.S. Espedal, R.C. Sharpley, S. Man, "An Eulerian-Lagranģian Localized Adjoint Method for Advection- Dispersion Equations in Two Dimensions and its Comparison to Other Schemes", to appear, SIAM J. Sci. Comp., 1997. 


\section{The University of Texas}

This report describes briefly the work of the Center for Subsurface Modeling (CSM) of The University of Texas at Austin (and Rice University prior to September 1995) on the Partnership in Computational Sciences Consortium (PICS) project entitled Grand Challenge Problems in Environmental Modeling and Remediation: Groundwater Contaminant Transport. This project was funded by the U.S. Department of Energy (DOE) under contract No. DE-AC05-96OR22464 (and earlier contracts), and administered through the Center for Computational Sciences, Bldg 4500N. MS 6203, Oak Ridge National Laboratory, Oak Ridge, TN 37831. Other participants and work was performed by Texas A\&M University (Richard E. Ewing and Michael S. Pilant), Oak Ridge National Laboratory (ORNL-Kenneth Kliewer), Brookhaven National Laboratory (BNL-Ronald F. Peierls and Joseph E. Pasciak), the University of South Carolina (Robert C. Sharpley), Princeton University (Michael A. Celia), and SUNY Stony Brook (James Glimm and Brent Lindquist). The entire project is described in the full report; this report describes only the CSM contribution.

Activities at The University of Texas at Austin were centered within the Center for Subsurface Modeling (CSM) of the Texas Institute for Computational and Applied Mathematics (TICAM). The following members were involved in the project from The University of Texas at Austin and, prior to September of 1995, at Rice University. Faculty members were Mary F. Wheeler (Director of CSM), Todd Arbogast; Clint N. Dawson, and Joseph Warren. Research scientists and post doctoral researchers include Steve Bryant, Frederic d'Hennezel, Philip T. Keenan, Robert McLay, Douglas Moore, and Ivan Yotov. Graduate students include Ashokkumar Chilakapati, Lawrence C. Cowsar, Joseph Eaton, Fredrik Saaf, Carol San Soucje (Woodward), and Ivan Yotov.

These researchers, their work, the development of software connected with this project, and their publications and professional presentations were supported only in part by the U.S. Department of Energy (DOE) through the Partnership in Computational Science (PICS) Grand Challenge Program administered through 
the Center for Computational Sciences at the Oak Ridge National Laboratory. Support came also from other grants from the DOE, the U.S. National Science Foundation, and the State of Texas Governor's Energy Office.

\subsection{The Parssim1 and GCT simulators}

Parssim1 [UT-TR7] is a simulator written by CSM to develop and test algorithms and software needed for the PICS Groundwater Contaminant Transport (GCT) simulator. We first describe Parssim1, the Parallel Subsurface Simulator, Single Phase. Parssim1 is an aquifer or reservoir simulator for the incompressible, single phase flow and reactive transport of subsurface fluids through a heterogeneous porous medium of somewhat irregular geometry. It is also capable of simulating the decay of radioactive tracers or contaminants in the subsurface, linear adsorption, wells, and biorem ediation [UT-O3, UT-O5, UT3, UT8, UT-O17, UT-O19].

Although the code uses very simple rectangular data structures for efficiency and accuracy, the subsurface domain can be of irregular geometry. The subsurface domain is assumed to be described by a logically rectangular grid. A mapping technique is used to map the irregular, physical domain (with its hills, valleys, interna! faults and strata, etc.) to the rectangular, computational domain, without loss of accuracy or efficiency.

The code can run in serial on a single processor, or on a massively parallel, distributed memory computer or collection of computers (using MPI or PVM). The code is portable, and has been run to date on several large parallel machines (Intel Paragon, IBM SP2, and Cray T3E) and on various serial machines (Sun Sparc2, IBM RS6000, and SGI Octane). Computational results indicate that the code has very good parallel scaling properties. We use domain decomposition to compute in parallel. The grid is divided into subdomains, one for each parallel processor. Each subdomain is given roughly the same number of cells. Each processor is responsikle for the simulation only in its subdomain. The individual processors send information to each other during the computation.

The flow, advection, diffusion/dispersion, and geochemistry subproblems are 
solved independently using a time splitting technique $[2,3]$. Thus, the code is very modular, and consists of the four main parts: driver, flow, transport, and chemistry. The driver routines are responsible for the user interface (input and output) as well as mankiging the coupling between the flow and transport routines. Chemistry is called from within the transport routines.

Flow is simulated with a package called Parcel [UT-TR4] It allows for the simulation of incompressible, single-phase, saturated flow with wells on geometrically general domains (but logically rectangular), and it uses a locally conservative, cell-centered finite difference scheme.

The transport routine ParTrans allows the simulation of multiphase transport with linear sorption, radionuclide decay, simple (specialized) chemical reactions, and wells on general geometry. Transport is simulated using a locally conservative method of charecteristics called the Characteristics-Mixed Finite Element Method (CMM) or a Godunov Method.

The general chemistry routine handles both equilibrium and kinetic reactions. For equilibrium reactions, it uses an interior-point algorithm for the minimization of the Gibbs free energy, and is therefore relatively robust, even when mineral phases precipitate into existence or dissolve away.

We now describe the GCT simulator. Similar to Parssim1, the GCT simulator consists of four main parts: driver, flow, transport, and chemistry. The transport and chemistry routines are essentially identical to those found in Parssim1. The driver routines are very similar and use much of the same software as found in Parssim1. Only the flow routines are significantly different in GCT. These are the result of the Texas; A\&M, University of South Carolina, BNL, and Princeton efforts, as described elsewhere. Because of the time splitting approach used, the flow routines in Parssim1 can be relatively easily replaced by the PICS flow routines to form $\mathrm{GC} \Gamma$, although substantial changes to the driver routine to accommodate new input and data structures are also required. It should be noted, however, that the most advanced state of development (and debugging) of the driver, transport, and chemistry routines appears only in Parssim1; earlier 
versions were incorporsıted in GCT.

\subsubsection{Algorithm and Software Development for Flow}

The Parcel flow packaye [UT-TR4] was developed at CSM primarily independently of PICS as a solver for second order elliptic partial differential equations. It uses an efficient doraain decomposition solution procedure that scales nearly linearly in parallel, the Glowinski-Wheeler [5] domain decomposition procedure. This involves solving a interface problem [UT5, UT-O8]. The subdomain linear system is solved directly.

Parcel was interfaced to Parssim1 through routines that set up the physical problem of incompressible saturated flow with various types of boundary conditions and wells. This simple flow situation allowed for more rapid development of the other routines.

A locally mass conservative, logically rectangular cell-centered finite difference procedure, developed primarily through the PICS project, is used to discretize the equations. This method is based on the expanded mixed finite element method, handles tensor permeabilities accurately [UT10], and extends to non-rectangular geometry by a preprocessing of the coefficients by a mapping technique [UT13] (see also [UT-O6, UT-09, UT-O10, UT-O13, UT-O18]). The efficiency of rectangular cell-centered finite differences is maintained. The finite difference stencil is a compact, 19-point stencil in three dimensions (the $3 \times 3 \times 3$ cube less the 6 corners). The compactness of the stencil makes the technique efficient in parallel applications. It was shown rigorously that the discrete solution to the scheme converges at the optimal rate to the true solution to the differential equations; moreover, at nodal points, there is superconvergence of the pressure and, on smooth grids, also of the mass flux. This extra accuracy in the flux between grid cells is important for subsurface flow, since the mass flux is of primary interest in transport problems. Similar results were obtained for triangular and tetrahedral meshes [UT-O4, UT13].

At the close of the project, extensions to multi-block domains were being 
pursued (though not primarily by the PICS effort). These are grids formed by partitioning the domain into large "blocks," and imposing a grid independently on each block. Since the grids may not match across the interface, special care must be taken there. In one approach, a discrete "mortar" space is defined on an interface grid to impose conservation of mass and continuity of pressure [UT-O11, UT-O16, UT15, UT7]. In a second approach, these are obtained by the imposition of ofposing Robin type interface boundary conditions [UT11]. Theoretical error analysis and numerical testing show that the schemes are optimally convergent.

Work was begun on an operator based upscaling technique to better handle subgrid effects, such as heterogeneities in the permeability and the exact size and location of wells. The echnique is efficient and shows promise [UT-O21].

\subsubsection{Algorithm and Software Development for Transport}

Three options can be selected for the solution of the advection subproblem.

Characteristics-Mixed Method (CMM). An explicit characteristics method, a type of Eulerian-Layrangian or ELLAM method, called the CharacteristicsMixed Method, was developed, numerically analyzed, and implemented [UT-O1, UT4]. Mass is advectied in time by a backward difference approximation. Not merely points, but entire grid cells are tracked backward along the characteristics (i.e., streamlines), and the mass from the previous time level in this region is given to the grid cell c.t the current time level. A postprocessing of the previous mass distribution achisves theoretically and numerically increased accuracy. The scheme has minimal numerical dispersion and is theoretically locally conservative. No CFL time step corstraint is imposed (other than that related to the domain decomposition), so relatively large time-steps can be taken.

The code scales nearly linearly in parallel [UT-TR1]; however, the method suffers from numerical mass and/or volume imbalances in implementation. It is also relatively computationally expensive.

Since adsorption processes change the characteristic speed of some chemical 
species, when reactive transport is simulated, it may be advantageous to take relatively small time steps. This prevents inaccurate approximation of time during which species are in contact and can therefore react. Thus, we implemented the other two advection options below.

Higher Order Grodunov Method (HOG). An explicit, formally second order Godunov method was added to Parssim1 for advection [1]. A postprocessing step improves the order of accuracy (except near sharp fronts or shocks). The scheme has a CFL time step constraint, so relatively small time-steps must be taken. The scheme has very little numerical dispersion, and is locally mass and volume conservative. Fiach time step, though small, is computationally relatively inexpensive.

A direct comparison of the two advection schemes was performed on a test case related to the Oak Ridge site. In this case flow is down a hillside toward a pit where strontium was stored. We simulated flow of a tracer for 40 days using a two-dimensional $40 \times 40$ grid and compared solutions generated by the HOG and characteristic methods in the absence of dispersion. The results were very similar. The characteristic method exhibited slightly less numerical diffusion. In this run the time step for the characteristic method was 6 times larger than a CFL constraint would allow, but the higher-order Godunov method was much faster per time-step. Thus the overall run time for the HOG method was less than that required for the characteristic method.

First Order Godunov Method (FOG). The higher order Godunov Method can be used without the postprocessing step, resulting in the first order Godunov method for advection.

Diffusion/Dispersion. This subproblem is solved by the cell-centered finite difference technique used for the flow problem, as described above. Note that Dispersion must be represented as a tensor, with (generally) greater longitudinal mixing in the direction of flow as opposed to the transverse directions. A simple Jacobi preconditioned conjugate gradient technique is sufficient to solve the resulting linear syster. 
Nonlinear Sorption. Studies and numerical computations on especially the long time limit profiles of nonlinear sorptive pulses was performed [UT1, UT2, UT6, UT9, UT12, UT-O7, UT-O12]. These studies showed that the underlying algorithms for transport and nonlinear sorption were accurate, altough Parssim1 uses somewhat different numerical techniques for sorption: either simple linear adsorption or sorption computed in the geochemistry routines as a phase change.

\subsubsection{Algorithm and Software Development for Geochemistry}

After gaining experience with bioremediation modeling [UT3, UT-O2, UT-O3, UT-O5], CSM developed and tested a geochemical reaction simulator [UT-O15, UT-TR6, UT-O20]. The local governing equations for the geochemical system are a mixture of differential and algebraic equations, including elemental mass balance equations. Discretizing the differential/algebraic system implicitly in time, which is necessary to correctly couple reactions and minimize time step restrictions, results in a system of nonlinear equations. This system can be difficult to solve numerically. One reason is that the species concentrations and rate parameters can differ by many orders of magnitude. Another is the physical requirement that species concentrations be nonnegative. The non-differentiable character of the equilibria for precipitation-dissolution reactions adds a particular complication: the possibility that a mineral can be present imposes an inequality constraint on the species concentrations, which becomes an equality only when the mineral is actually present. To handle such constraints requires iterations through different comininations of minerals. This iteration introduces a variety of problems regarding convergence, efficiency, robustness and stability.

As a first attempt at modeling geochemistry, we obtained the batch chemistry simulator KEMOD from George Yeh at Penn State University [6] and incorporated it into our transport module. In order to improve the robustness of the KEMOD routine, sereral enhancements were made. We incorporated a global Newton line-search procedure, and introduced variable scalings/transformations to handle the differences in magnitude between concentrations and rate param- 
eters. We also investigated alternative strategies for selecting correct mineral assemblage, and modified the stopping criteria. These modifications have made the code more robust, but they are not sufficient for all the cases under consideration; in particular, precipitation/dissolution reactions are still problematic.

As an attempt to create a more robust and rigorous procedure, we recast the batch calculation as a free energy minimization problem and developed the new simulator. This approach is often used in calculating phase partitioning in multi-phase flow simulation. The result of this formulation is the minimization of an energy functional, subject to elemental mass balance equations and inequality constraints (concentrations are nonnegative). For solving this system we use of an interior-point algorithm, developed by Richard Tapia et al., at Rice University [4, UT-O14, UT-TR5]. Calculations for simplified aqueous chemistry showed improved robustness over the modified KEMOD routine.

Work was begun cn load balancing the geochemistry work in parallel. In a typical subsurface problem, reaction fronts travel through the domain. These fronts are associated with increased computational effort, and therefore require a different distribution of work than for the flow and transport, which is divided evenly by a domain decompositiun that assigns an equal number of grid cells to each processor. Initial. results show dramatic improvements after load balancing the reaction computations [UT-O22].

\subsubsection{Documentation and User Interface Software Development}

A complete, fully indexed user's manual was developed for Parssim1 [UT-TR7]. The manual describeis briefly the code's capabilities and algorithms, and then provides a detailed discussion of the input and output files.

The user interface to Parssim1 allows a reasonable amount of flexibility without making the code difficult to use. It is not required that the advanced features be used to run the code. Parallelism is entirely transparent to the user.

Information is provided item-by-item in a free format style (items are separated by any number and combination of space, tab, and carriage return, as well 
as comma, semicolon, and colon). Comments are allowed after the pound sign. Thus, data can be set up by the user in a meaningful way. The input can be divided by the user into separate files if that is convenient, say either to separate grid information from species information from algorithm parameters, etc., or to place large data sets in separate data files. Errors in the input file(s) are identified by type of error and file and line number of occurrence, so that problem specification input errors can be reliably and rapidly corrected.

Physical units can be given inconsistently. The user interface allows for automatic units conversion and checking. Thus one gram per cc can be given in cgs units as " 1 " or as " $1[\mathrm{~g} / \mathrm{cc}]$." The latter is one gram per $\mathrm{cc}$ in whatever system of units is used, and the quantity given this value must require the physical units of mass per volume (or an error will be flagged). See the manual for a complete description of capabilities.

Parssim1 was conpected to the Waterways Experiment Station's GMS frontend at ORNL and used successfully. Parssim1 was also successfully connected to the pv3 package to allow interactive visualization of data in parallel.

\subsubsection{A Scripting lsanguage for GCT}

An input specification "scripting language" was developed to enabie PICS to unify the input specification to the GCT code. This scripting language was based loosely on the "kScript" language of Phil Keenan [UT-TR3]. This new input specification allows the user to specify input data in a uniform manner, it will allow us to add features to the code without making older data sets obsolete, and it will eventually allow us to add code to perform text-based, interactive simulation. In the first phase of this project, a preprocessor was under development at BNL to translate the new input script into the old data files, so no interactivity is yet possible.

All data can be entered into GCT through data files prepared using the preprocessor by issuing commands scripted in this highly flexible, free format style

scripting language. 'The input script can be given interactively from the key- 
board, it can be prepared ahead of time and read directly from one or more input files, or it can be given in a combination of these two ways. Most data items have a default value, so generally only a small amount of data needs to be explicitly given to run the code successfully.

The input script consists of a series of commands, each describing some action to be taken. A single command may span multiple lines, and multiple commands may be on the same lije. A command has a command name and optionally one or more arguments. An argument may be a subcommand name, the name of a data item (such as a variable, array, or function), or the data itself.

The name of a data item is also the name of a command to set it to a value. The value can be specified as an arithmetical expression of numbers and/or other variable names. For example " $2 * \mathrm{~cm}$ " can be used to declare a length of $2 \mathrm{~cm}$ (provided that the unit " $\mathrm{cm}$ " has been defined appropriately). Thus, among other things, the language explicitly allows easy units conversion.

A command can be repeated with different arguments. For example, the user can prepare a script file with a different set of defaults than are provided automatically, read these defaults, and then modify them for the case at hand. The latest instance of the command overrides the effects of all former instances.

Prototypes of this system were developed; however, this work on a scripting language for GCT was; not completed by the end of the PICS project.

\subsection{The Eye Visualization Tool}

Eye [UT-TR2] is a interactive viewer for polyhedral data. The polyhedral data is produced by tools that processes some form of scientific data and produce polygons from it. Currently available tools include iso-contour generators, crosssection generators, and steady-state flow-line generators for data arranged topologically as cubic grids. Eye is aware of these tools, and the user can invoke them from within Eye. Other tools can be built and integrated easily into Eye as needed, such as tocils for producing iso-surfaces from scattered points, or tools for generating time-varying flow lines. 
Eye displays three-dimensional data projected onto a flat screen; however, it actually represents data in up to five dimensions. The data that Eye receives actually consists of a collection of simplices (points, segments, triangles, tetrahedra, ...), with each vertex of the simplex a tuple of data. Conventionally, these tuples are displayed as the $x$-, $y$ - and $z$-coordinates of a point, its time, and its value. The $z$-coordinate is projected away according to where the user places his "eye" with respect to the object viewed. The time coordinate is intersected away according to where the user sets a clock. The value coordinate is mapped onto a color spectrum.

The geometric datia that Eye receives can be viewed as filled-in flat-shaded polygons, as a wire-frame model, or as a point cloud. The geometry can be viewed from arbitrary orientarions, with lighting from several directions and with parts clipped away to reveal the most relevant parts. The figure can be moved across the screen, distorted to increase or lessen the apparent depth of the figure, or repainted to reflect a shift or stretch in the value dimension.

Eye is designed fo: portability; with appropriate configuration, Eye can be installed on any workstation that supports version 4 or higher of the $\mathrm{X}$ Window System, release 1.1, and provides a $\mathrm{C}++$ compiler. Versions that exploit specialized gräphics libraries and hardware for better performance are under development. Eye can display its images on paper as well; it can generated encapsulated Post-Script for an image in a format compatible with the Idraw program distributed with the freely available InterViews user-interface library. Thus, it produces pictures tha1; can be rearranged manually for better presentation.

Eye presents a graphical interface with three main components: the menu-bar across the top-left, the gadgets on the right, and the viewport that dominates the application window. The viewport is the region where the object being viewed is displayed. An optional bounding box about the object provides information on the current object possition. 


\subsection{Model Applications}

The following applications of Parssim1 have been performed to date. These applications were only partially supported by PICS, but they represent application of the codes supported by PICS.

\subsubsection{Benchmark Problems}

At the PNNL-hosted Workshop on Subsurface Reactive Transport (29 Oct. to 1 Nov., 1997) a set of benchmark problems were set up in order for the invited participants to compare reactive transport codes. Parssim1 functioned very well on these tests. Examples included a flow in a $2 \mathrm{D}$ parabolic velocity field with a conservative tracer, providing a rigorous test of the ability of a code to control numerical dispersion. 'The method of characteristics option in Parssim1 handled this problem very well, while the higher-order Godunov scheme exhibited larger dispersion. The test :oroblem was particularly well suited to particle tracking transport schemes. Extensions of the test problem to simple kinetics were also handled well by Parssim1, and it should be noted that general chemical reactions of the sort incorporated in Parssim 1 are difficult to implement in particle tracking schemes.

Another benchmark involved the transport of mixed waste (heavy metal cations with organic ligands) through a 1D medium. The complex chemistry included rate limited sorption and biodegradation, as well as complexation. Parssim1 replicated the benchmark results. The extension to very fast kinetic reactions introduced some minor numerical difficulties; converting the fast kinetics to equilibrium reactions gave essentially the same concentration profiles without the numerical problems.

A particularly inst]uctive benchmark involved the speciation of a redox-sensitive solution with pyrite. This proved to be an extremely rigorous test of the mass balance of any code. As a matter of fact we were able to demonstrate discrepancies in the reported solutions to the problem.

Another benchmark involved the migration of a square concentration wave in 
a 2D domain. The flow field was transverse to the coordinate axes, again giving a severe test of a code's capability to avoid numerical dispersion. The method of characteristics scheme preserved the square wave well, though it was costly to compute. The higher-order Godunov scheme exhibited some dispersion but did run more rapidly.

\subsubsection{Site Characterization}

Partitioning tracers are a novel technology for locating NAPLs in the subsurface and assessing their saturations. This approach offers significant cost advantages over other characterization technologies, but it requires very powerful forward simulation models in order for the inversion problem to be feasible. The general chemistry capabili1ies in Parssim1 make this forward modeling straightforward. We have carried out several test cases with multiple wells, heterogeneous rock properties and heterogeneous distributions of NAPL phase. These clearly demonstrate the different velocities of conservative and partitioning tracers in the presence of the NAPL phase.

\subsubsection{Radionuclide migraticn}

One of the most intriguing applications of Parssim1 has been the investigation of radionuclide migration on the Oak Ridge Reservation [UT14]. Waste pits and trenches on the Reservation were filled with low-level radioactive waste during the Manhattan Project. The $\mathrm{pH}$ of the waste was increased in order to promote precipitation of radioactive cations as hydroxyl salts. Simulation of transport of this high $\mathrm{pH}$ waste shoved remarkable behavior in form of a pulse of radionuclide moving at approximately tracer velocity. This result is completely unexpected from classical chromatography theory, but it has been verified independently by numerical means. More importantly, the prediction explains the field observation of rapid radionuclide movement. An investigation of the underlying mathematics of this mode of propagation continues, as well as further simulation of the field situation. 


\subsubsection{Pump-and-treat Remediation Simulation}

The mixed-waste (heav! metal plus organics) benchmark problem described above was extended to provide an example of a pump-and-treat remediation strategy. A waste source was imposed for 500 days in a small region of the recharge zone of an aquifer, in which an east-to-west flow field prevailed. The aquifer was highly heterogeneous in perme ability, but its sorption properties were assumed constant with position. Three wells were turned on in a region downstream of the contaminant plume after 1250 days of simulated time. This 3D simulation showed the importance of correctly scaling up laboratory derived conditions. The naturally occurring microbe population decreased very rapidly in this simulation, indicating that the microbe death rate kinetics used in the lab scale benchmark problem would give a much more optimistic prediction of natural attenuation in the lab than would be obtained in the field.

\subsubsection{Well Stimulation}

The stimulation of wells with acid is an important application of reactive flow. Such treatments are cauried out in thousands of oil and gas wells annually, as well as in many injection wellis operated by waste disposal conpanies. When concentrated hydrofluoric and hydrochloric acids contact sedientary rocks, a large suite of dissolution reactions occurs at a wide range of rates. High concentrations of mineral ions are generıted, making many precipitation reactions possible, along with several important secondary dissolution reactions. Overlaying this chemical complexity is the near-wellbore flow field. Previous studies of acid stimulation usually assume a radial flow field, but this assumption can greatly oversimplify local variations due to the geometry of perforations and the distribution of permeability. The competition between advection and reaction is critical for determining local extents of reaction, and so variations at this scale can be important. The rock itself is mineralogically heterogeneous, further complicating the problem. Thus the question of what is the optimum design for well stimulation remains open. 
We have simulated a variety of scenarios, the first goal being to evaluate whether crossflow in the vertical direction will compromise the effectiveness of a stimulation treatment. Thus far it appears that simple layered formations behave just as predicted from simpler models. Work is still underway to determine how this conclusion changes when flow is radial rather than linear, with a consequent variation of Damkohler number (ratio of characteristic reaction time to characteristic advection time) along the flow field. We are also investigating the effect of heterogeneities, both mineralogical and hydraulic, in the near-wellbore region.

\subsubsection{Diagenesis}

As brines percolate through buried sediments over geologic time, mineral precipitation and dissolution can occur. These reactions can alter porosity substantially and can change permezbility by orders of magnitude. Thus an ability to predict how and where such reactions occur can greatly improve the understanding of flow fields in aquifers and reservoirs. Researchers in the Department of Geological Sciences at UT-Austin have produced a detailed description of a carbonate rock (the Lower Ismay in Utah) both in outcrop and at depth. We are using this data, along with constraints on possible fluid compositions derived from laboratory measurements, as input to Parssim1 for simulation of reaciive fiow through the sediment. Because the field and lab data so thoroughly characterize the rock, this will provide an excellert test of the model, providing insight into what chemical and physical mechanisins must have been at work.

\subsubsection{Biotic/Abiotic Competition}

Biodegradation reactions rarely occur in isolation; there is commonly competition between multiple microorganisms and multiple pathways for reaction. For example, inorganic reactions may consume or produce species involved in biodegradation. Biodegradation of toluene using a multi-component model illustrates how competition between components can affect the degradation rate. Parssim1 allows the user to select chemical and biological components for reactive transport 
modeling including kinetics and accounts for coupling between biotic and abiotic species. The model quantified the inhibition of toluene degradation when either benzene or pyrite competes with toluene for electron acceptors. Simplified uncoupled models will not account for this behavior, so it is important to collect site-specific data to determine whether chemically heterogeneous conditions exist before deciding whether to use simplified or multi-component models.

\subsubsection{Bioremediation}

Parssim1 has been used to quantify the migration of contaminants in complex flow geometries with a variety of chemical interactions. In order to compare the effects of different reaction pathways, we considered the case of a residual NAPL phase dissolving into a flowing groundwater, with subsequent biodegradation of the dissolved NAPL. The simulations involved from three to 27 species and two phases (flowing water, immobile NAPL). The flow of approximately 10 pore volumes of groundwater was simulated through a unit cube of porous medium which contains several regions of residual non-aqueous phase liquid (NAPL). A constant velocity is imposed at the $x$-faces of the cube; the $y$ and $z$ faces are no-flow boundaries. A $32 \times 32 \times 32$ grid was used to discretize the porous medium, and isotropic permeabilities were assigned to the grid blocks from a Gaussian distribution spanning 3 orders of magnitude. The spatial distribution of permeability causes a very heterogeneous flow field, despite the simple boundary conditions.

The residual NAPI, phase dissolves into the flowing groundwater. The rate of dissolution depends on the difference between the local aqueous NAPL concentration and the maximum possible concentration (i.e. the concentration in equilibrium with the residual phase, which is $0.1 \mathrm{~mol} / 1$ in this example). In the base case, in which there are no naturally occurring processes to degrade the NAPL, the contamination plume expands downstream of the NAPL sources. The groundwater contiains dissolved oxygen at typical background levels. Thus when a uniform distrioution of microbes is placed in the porous medium, the microbes utilize the ox:ygen to degrade the dissolved NAPL. Consequently the 
contamination plume is much smaller than in the base case.

In natural environments, the dissolved oxygen may participate in many other reactions. For example. reducing minerals such as pyrite will consume dissolved oxygen until the porous medium reaches Eh equilibrium. Such redox reactions will delay the propagation of the injected oxygen concentration through the porous medium. In this example case, all the incoming oxygen was consumed by inorganic redox reactions (assumed to proceed to thermodynamic equilibrium instantaneously) during the first year. This leaves no oxygen for biodegradation. Consequently the contamination plume is as severe as if no microbes were present. This illustrates the importance of considering all the chemical interactions in a system, both biotic and inorganic.

If the redox reacticns occur at a finite rate, rather than going to thermodynamic equilibrium, more oxygen is available for biodegradation. The amount available depends on the rate of redox reaction. In this case study, the redox consumption during the first year of flow was so fast that little biodegradation occurred. In this case the contamination plume is only slightly smaller than in the case of equilibrium redox reactions.

After three years of simulated flow, the base case contamination plume is still quite large. In the case of biodegradation only, the natural attenuation process has greatly reduced the extent of the plume; the contamination is limited to the immediate vicinity of the residual NAPL phase. However, if substantial pyrite is present, the equilibrium redox front will have propagated only a small distance even after three years, consuming nearly all the incoming oxygen. If the redox reactions are rate-limited, enough oxygen is getting into the porous medium after three years to substantially reduce the contamination plume.

Ultimately the inconing oxygen changes the Eh of the porous medium, so that eventually oxygen beccmes available for biodegradation, even if large amounts of pyrite are present. All the situations in which microbes are present exhibit smaller contamination plumes than the worst case. 


\subsection{Prospective Model Applications}

The following applications of Parssim1 are being investigated in the CSM.

\subsubsection{Heavy Metal 'Transport}

We have available a data set from a small chemical plant, the soil of which is contaminated with heavy metals including arsenic and chromium. The data includes the flow field and extensive chemical analysis of samples from monitoring wells. A pump-and-treat remediation scheme has started on site, and siting of additional wells is currently being studied. The sorption, cation exchange and precipitation of heavy metals have a dramatic effect on their migration in the subsurface, and a mocleling study of the site would provide important insight as alternative remediation schemes are considered. Parssiml's ability to handle general inorganic chemistry and detailed flow fields, including wells, would be very useful in this case.

\subsubsection{Coal Ash Leaching}

We have an extensive data set from experiments conducted on the leaching of coal asiı. Processes have been developed which improve the combustion of coal so that many pollutanis which otherwise enter the flue gas instead remain in the ash. While these processes hold the promise of greatly reducing air pollution from coal-fired power plants, the question arises as to whether the pollution problem is merely being transferred from the atmosphere to the groundwater. Coal ash from these advanced combustion processes is particularly reactive, and the percolation of rainwater through an ash pile can result in highly alkaline effluent with significant metal loading. It would be of considerable practical interest to model both the leaching process and the migration of the leachate through the subsurface with Parssim1. The experimental data would provide a useful validation of available kinetic and thermodynamic parameters for heavy metals. 


\subsection{Refereed Publications}

[UT1] C. Dawson, C., J. van Duijn and M. F. Wheeler, Characteristic-Galerkin methods for contaminant transport with non-equilibrium adsorption kinetics, SIAM J. Numer. Anal., 31 (1994), 982-999.

[UT2] R. E. Grundy, C.,, J. van Duijn and C. Dawson, Asymptotic profiles with finite mass in one-dimensional contaminant transport through porous media: the fast reaction case, Quarterly Journal of Mechanics and Applied Math., 47 (1994), 69-106.

[UT3] T. Arbogast, C. N. Dawson and M. F. Wheeler, A parallel algorithm for two phase multicomponent contaminant transport, Applications of Math., 40 (1995), 163-174.

[UT4] T. Arbogast and M. F. Wheeler, A characteristics-mixed finite element method for advection dominated transport problems, SIAM J. Numer. Anal., 32 (1995), 404-424.

[UT5] C.L. Cowsar, J. Mandel, and M.F. Wheeler, Balancing domain decomposition for mixed finite element methods, Math. of Comp. 64 (1995), 989-1015.

[UT6] C.N. Dawson, High-resolution upwind-mixed finite element methods for advection-diffusioa equations with variable time stepping, Numerical Methods for Partial Differential Equations, 11 (1995), 525-538.

[UT7] Y.A. Kuznetsov and M.F. Wheeler, Optimal order substructuring preconditioners for mixed finite element methods on nonmatching grids, East-West J. Numer. Math. (1995), 127-143.

[UT8] T. Arbogast, S. Bryant, C. Dawson, F. Saaf, Chong Wang and M. Wheeler, Computational methods for multiphase flow and reactive transport problems arising in sulssurface contaminant remediation, J. Computational Appl. Math., 74 (1996), 19-32.

[UT9] C. Dawson, C., J. van Duijn and R. E. Grundy, Large-time asymptotics in contaminant transport in porous media, SIAM J. Appl. Math., 56 (1996), 965-993.

[UT10] T. Arbogast, M. F. Wheeler and I. Yotov, Mixed finite elements for ellip- 
tic problems with jensor coefficients as cell-centered finite differences, SIAM J. Numer. Anal., 34 (1997), 828-852.

[UT11] T. Arbogast and I. Yotov, A non-mortar mixed finite element method for elliptic problems on non-matching multiblock grids, Comp. Meth. in Appl. Mech. and Engng., 149 (1997), 225-265.

[UT12] C. J. van Duijrı, R. E. Grundy and C. Dawson, Limiting profiles in reactive solute transport, Transport in Porous Media, 27 (1997), 57-84.

[UT13] T. Arbogast, C'. N. Dawson, P. T. Keenan, M. F. Wheeler and I. Yotov, Enhanced cell-centered finite differences for elliptic equations on general geometry, SIAM J. Sci. Comput., 19 (1998), 404-425.

[UT14] L. Toran, S. Bryant, J. Saunders, and M.F. Wheeler, Sr mobility under variable $\mathrm{pH}$ : application of a coupled geochemistry and transport model, to appear in Groundwater.

[UT15] T. Arbogast, 1. C. Cowsar, M. F. Wheeler and I. Yotov, Mixed finite element methods on non-matching multiblock grids, SIAM J. Numer. Anal., Submitted.

\subsection{Other Publications}

[UT-O1] T. Arbogast, A. Chilakapati and M. F. Wheeler, A characteristic-mixed method for contaminant transport and miscible displacement, in Computational Methods in Water Resources IX, Vol. 1: Numerical Methods in Water Resources, T. F. Fussell et al., eds., Computational Mechanics Publications, Southampton, U.K. (1992), 77-84.

[UT-O2] A. Chilakapati, K.R. Robertson, and M.F. Wheeler, Three-Dimensional Bioremediation Mlodeling in Heterogeneous Porous Media, Computational Methods in Water Resources IX, Vol. 1: Numerical Methods in Water Resources, T.F. Russell et al., eds., Computational Mechanics Publications, Southampton, U.K. (1992), 299-316.

[UT-O3] T. Arbogast and M. F. Wheeler, A parallel numerical model for subsurface contaminant transport with biodegradation kinetics, in The Mathe- 
matics of Finite 1.lements and Applications VIII (MAFELAP 1993), J. R. Whiteman, ed., W'iley, New York (1994), 199-213.

[UT-04] T. Arbogast, C. N. Dawson and P. T. Keenan, Efficient mixed methods for groundwater flow on triangular or tetrahedral meshes, in Computational Methods in Water Resources X, Vol. 1, A. Peters, et al., eds., Kluwer Academic Publishers, Dordrecht, The Netherlands (1994), 3-10.

[UT-O5] T. Arbogast, C. N. Dawson and M. F. Wheeler, A parallel multiphase numerical model for subsurface contaminant transport with biodegradation kinetics, in Computational Methods in Water Resources X, Vol. 2, A. Peters et al., eds., Kluwer Academic Publishers, Dordrecht, The Netherlands (1994), 1499-1506.

[UT-06] T. Arbogast M. F. Wheeler and I. Yotov, Logically rectangular mixed methods for grourdwater flow and transport on general geometry, in Computational Methods in Water Resources X, Vol. 1, A. Peters et al., eds., Kluwer Academic Publishers, Dordrecht, The Netherlands (1994), 149-156.

[UT-O7] C. Dawson, Modeling of nonlinear adsorption in contaminant transport, Computational Methods in Water Resources X, A. Peters et al., eds., Kluwer, Dordrecht, pp. 233-240, 1994.

[UT-08] L. C. Cowsac, Some domain decomposition and multigrid preconditioners for hybrid mixed finite elements, $P h . D$. thesis, Department of Computational and Applied Mathematics, Rice University, April, 1994.

[UT-09] T. Arbogast;, P. T. Keenan, M. F. Wheeler and I. Yotov, Logically rectangular mixed methods for Darcy flow on general geometry, note SPE 29099 , in Proceedings of the 13th SPE Symposium on Reservoir Simulation, held in San Antonio, Texas, Society of Petroleum Engineers (February 12-15, 1995), 51-59.

[UT-O10] T. Arbogast, Mixed Methods for Flow and Transport Problems on General Geometry, in Finite Element Modeling of Environmental Problems, G. F. Carey, ed., Wiley, Cichester, England, (1995), 275-286.

[UT-O11] M. F. Wheeler and I. Yotov, Mixed finite element methods for mod- 
eling flow and transport in porous media, in International Conference on Mathematical Modeling of Flow through Porous Media, Saint Etienne, France, A. P. Bourgeat et al.,eds., World Scientific (1995), 337-357.

[UT-O12] C. Dawson, Contaminant transport with nonlinear, nonequilibrium adsorption kinetics, Finite Element Modeling of Environmental Problems, G. F. Carey, ed., Wiley, New York, pp. 265-274, 1995.

[UT-O13] T. Arbogasi;, M. F. Wheeler and I. Yotov, Logically rectangular mixed methods for flow in irregular, heterogeneous domains, in Computational Methods in Water Resources XI, vol. 1, Á. A. Aldama et al., eds, Cmputational Mechanics Publications, Southampton, (1996), 621-628.

[UT-O14] S. Bryant, IT. Saaf, R. Tapia, and M.F. Wheeler, Computing General Chemical Equilibıia with an Interior-point Method, Computational Methods in Water Resourses XI, Vol. 2, A.A. Aldama et al., eds, Computational Mechanics Publications Southampton, U.K., (1996), 201-209.

[UT-O15] F. Saaf, A study of reactive transport phenomena in porous media, Ph. D. thesis, Rice University, Houston, Texas, 1996.

[UT-O16] I. Yotov, Mixed finite element methods for flow in porous media, Ph. D. Thesis, Rice University, Houston, Texas, May 1990 TR96-1j9, Dept. Comp. Appl. Malih., Rice University and TICAM report 96-23, University of Texas at Austin.

[UT-O17] M. F. Wheeler, T. Arbogast, S. Bryant, C. N. Dawson, F. Saaf and Chong Wang, New computational approaches for chemically reactive transport in porous midia, in Next Generation Environmental Models and Computational Methods (NGEMCOM), Proceedings of the U.S. Environmental Protection Agency Workshop (NGEMCOM), G. Delic and M.F. Wheeler, eds., SIAM, Philadelphia (1997), 217-226.

[UT-O18] T. Arbogast, C. N. Dawson, P. T. Keenan, M. F. Wheeler and I. Yotov, The application cf mixed methods to subsurface simulation, in Modeling and Computation in IBnvironmental Sciences, Proceedings of the ICA seminar on Modelling and Computation in Environmental Sciences, Univ. of Stuttgart, 
R. Helmig et al., eds., Notes on Numerical Fluid Mechanics, 59, Vieweg Publ., Braunschweig, (1997), 1-13.

[UT-O19] J. Eaton, C...V. Dawson, and M.F. Wheeler, Transport of Multispecies Components with Biological and Chemical Kinetics, Modeling and Computation for Applications in Mathematics, Science, and Engineering, J. Jerome, ed., Oxford University Press, Oxford, England, 1997.

[UT-O20] M.F. Wheeler, Transport of Multispecies Contaminants in Porous Media, in Nonlinear Applications, INRIA (1997), 1-70.

[UT-O21] T. Arbogast, S. E. Minkoff and P. T. Keenan, An operator-based approach to upscaling the pressure equation, in Computational Methods in Water Resources XII, (1998), to appear.

[UT-O22] M. F. Whee.er, T. Arbogast, S. Bryant and J. Eaton, Efficient parallel computation of spatially heterogeneous geochemical reactive transport, in Computational Methods in Water Resources XII, (1998), to appear.

\subsection{Technical Reports}

[UT-TR1] T. Arbogast, C. N. Dawson, D. Moore, F. Saaf, C. San Soucie, M. F. Wheeler and I. Yotov, Validation of the PICS transport code, Department of Computational and Applied Mathematics, Rice University, Houston, Texas, (1993).

[UT-TR2] P. Cheng, :M. Wells, D. Moore, Eye: 3D Graphics Visualizer User's Guide, Rice UNivarsity (1994).

[UT-TR3] P.T. Keenan, kScript User Manual, Version 2, TICAM Tech. Report,

The University of Texas at Austin, December 1995.

[UT-TR4] L. C. Cows.ar, C. A. San Soucie, and I. Yotov, Parcel v1.04 user guide, Tech. Rep. TICAM 96-28, Texas Institute for Computational and Applied Mathematics, The University of Texas at Austin, June 1996.

[UT-TR5] F. Saaf, A user's manual for nipsf: Nonlinear interior-point solver, fortran, Tech. Rep., TR96-24, Department of Computational and Applied Mathematics, Rice University, Houston, Texas, 1996. 
[UT-TR6] F. Saaf and S. Bryant, A user's manual for the geochemistry module in parsim 1 reactive flow and transport code, tech. rep., Center for Subsurface Modeling, Texas Institute for Computational and Applied Mathematics, The University of Texas at Austin, Austin, Texas, Jan. 1997.

[UT-TR7] T. Arbogast;, User's Guide to Parssim1: The Parallel Subsurface Simulator, Single Phase, The Center for Subsurface Modeling, Texas Institute for Computationa. and Applied Mathematics, The University of Texas at Austin, Austin, Texas, (1998).

\subsection{Presentations}

1. M.F. Wheeler, T. Arbogast, S. Bryant, C. Celentano, C.N. Dawson, P.T. Keenan, H. Klie, F. Saaf, C. San Soucie, and I. Yotov. All work was discussed at the Center for Subsurface Modeling Industrial Affiliates Annual Meetings from 1992-1997. This program has attracted the support of several major petroleum companies and a few computer companies.

2. M.F. Wheeler, T. Arbogast, C.N. Dawson, D. Moore, and J. Warren, video presentation on, "A demonstration of the Rice transport code," Supercomputing '9\%, Minneapolis, Minnesota, November, 1992.

3. T. Arbogast, "A characteristics-mixed method for advectior dominated transport problems," at the Institute for Mathematics and its Applications, University of Minnesol,a, summer program on Environmental studies: mathematical, computational, and statistical analysis, organized by M. F. Wheeler, J. Chang, M. Ghil, L. McTigue, J. Seinfeld, and P. Switzer, July 6-31, 1992.

4. T. Arbogast, "A characteristics-mixed method for advection-dominated transport," at the Texas Finite Element Circus, the Texas Institute for Computational Mechanics (TICOM), University of Texas, Austin, Texas, April, 1992.

5. C. N. Dawson, "Gudunov Mixed Methods for Nonlinear Contaminant Transport," Texas Finite Element Circus, University of Texas, March 1992.

6. C. Dawson, "Mixєd Finite Element Methods on General Geometry for Flow Through Porous Media," Dept. of Mathematics and Infomatics Delft Univer- 
sity of Technology, Netherlands, May 1992.

7. C. N. Dawson, "Large Time Behavior of Solutions for Contaminant Transport Problems in One Space Dimension," Mathematical Problems in Flow in Porous Media, Oberwolfach, Germany, June 1992.

8. C. Dawson, "Error Estimates for Godunov Mixed Methods Applied to Nonlinear Contaminan: Transport," Department of Mathematics, University of Houston, October :.2992.

9. M. Wheeler, "A Mixed-Characteristic Method for Contaminant Transport," Institute for Mathematics and Its Applications (IMA) and Mathematics Department, the University of Minnesota, Minneapolis, Minnesota, February 28, 1992.

10. M.F. Wheeler, "Three-Dimensional Bioremediation Modeling in Heterogeneous Porous Media," "Scientific Computation on Massively Parallel Machines" and "Mixed Characteristic Methods for Linear Advection Problems," Distinguished Visitior Series on Challenges for Computational Mathmetics in the 1990's, Mathematical Sciences Department, Clemson University, Clemson, South Carolina, March 9-12, 1992.

11. M. Wheeler. "A Mixed-Charact,eristic Method for Contaminant Transport" Plenary Address, International Conference on Differential Equations and Mathematical Physics, Georgia Tech, Atlanta Georgia, March 22, 28, 1992.

12. M. Wheeler, "Parallel Algorithms for Energy and Environmental Problems," Texaco Research and Developmemt, Houston, Texas, April 9, 1992.

13. M.F. Wheeler, "Characteristic Finite Element Methods for Modeling Transport Phenomena in Porous Media," the 28th Dutch Mathematics Congress, Delft University, Netherlands, April 22, 1992.

14. M.F. Wheeler, "Modeling Contaminant Transport of Toxic Waste Sites in Porous Media," University of Houston, Environment and Immunolgy Conference, Invited Spec,ker, May 1992.

15. M.F. Wheeler, "T.hree-Dimensional Bioremediation Modeling in Heterogeneous Porous Media," Water Resources IX, International Conference, invited 
speaker, Denver, June 1992.

16. M. Wheeler, "Modeling of Biodegradation of Contaminants in Groundwater," Institute for Mathematics and its Applications, University of Minnesota, Workshop on Environmental Problems, July 1992.

17. M. Wheeler, "Modıling Flow in Porous Media," International Congress on Nonlinear Analysis, Tallahasse, Florida, Invited Speaker, August 1992.

18. M.F. Wheeler, "Hi;gh Performance Computing in Modeling Flow in Porous Media," Cray Techoology Symposium, Houston, Texas, invited speaker, October, 1992.

19. M.F. Wheeler, "Characteristic Methods for Modeling Transport Dominated Flow Problems," Batalle Pacific Northwest Laboratory, invited speaker, August, 1992.

20. M.F. Wheeler, "Perallel Domain Decomposition Algorithms for Mixed Finite Element Methods," University of Kentucky Center for Computational Science, invited sp»aker, December 1992.

21. M.F. Wheeler, "Three Dimensional Bioremediation Model for Porous Media," AGU National Meeting, San Francisco, California, December 9, 1992, with Kyle Robinson, Batalle Pacific Northwest. Laboratiory.

22. M.F. Wheeler, "Mithematical Modeling in Porous Media," Mathematics Association of America, State of Texas Meeting, Houston, Texas, April 11, 1992.

23. M.F. Wheeler, "Parallel Algorithms for Modeling Flow in Porous Media," Supercomputer '92, invited speaker, Minneapolis, Nov. 1992.

24. M.F. Wheeler, "Rice Flow in Porous Media," Industrial Meeting with the Shell Research Group, Rice University, December 8, 1992.

25. T. Arbogast, "Coraputational justification of a dual-porosity model for twophase flow in fractured media," Second SIAM Conference on Mathematical and Computationcl Issues in the Geosciences, Houston, Texas, April, 1993.

26. T. Arbogast, "A ch caracteristics-mixed method for contaminant transport and miscible displacement," SIAM Conference on Mathematical and Computational Issues in the Geosciences, Houston, Texas, April, 1993. 
27. T. Arbogast, "Equations with dual-porosity microstructure for modeling flow in fractured porous media," Differential Equations Conference, Ohio University, Athens, OH, August, 1993.

28. T. Arbogast, "Characteristic and mixed methods for approximating advectiondiffusion equations." Georgia Tech, Atlanta, Georgia, November, 1993.

29. T. Arbogast, "Mixed methods for flow and transport problems on general geometry", Workshop on Finite Element Modeling of Environmental Problems, University of Texasi, Austin, Texas, March 4-5, 1994.

30. C. Dawson, "Numerical Simulation of Flow Through Porous Media," Dept. of Mathematics and Infomatics, Delft University of Technology, Delft, Netherlands, May 1993.

31. C. Dawson, "Modeling of Multiphase Flow in Porous Media," Dept. of Environmental Engineering, Rice University, November 1993.

32. M.F. Wheeler, "Parallel Algorithms for Modeling Flow in Porous Media," AMS/MAA Invited Speaker, the American Mathematical Society National Meeting, San Antcnio, January 1993.

33. M.F. Wheeler, "Characteristic Mixed Finite Element Methods for Modeling Transport Dominated Flow Problems," DOE, Sandia National Lah, invited speaker, February 1993.

34. M.F. Wheeler, "Computational Science Programs" \& "Parallel Algorithms for PDE's" Depariment of Mathematics, Trinity University, February 1993.

35. M. F. Wheeler, "Parallel Algorithms for Reservoir Engineering and Groundwater Modeling," sIAM, Norfolk Parallel Computation Meeting, Invited Minisymposium Speaker, Norfolk Virginia, March 1993.

36. M. Wheeler, "Advanced Numerical Algorithms for Groundwater Modeling," Lawrence Livermore Laboratory, invited speaker, March 1993.

37. M.F. Wheeler, "Domain Decomposition for Mixed Finite Element Methods for Elliptic Equations," VI International Domain Decomposition Meeting, Cuomo, Italy, June 1993. 
38. M.F. Wheeler, "Parallel Algorithms for Modeling Flow in Porous Media," Rice Mechanical Engineering Department, Colloqium Speaker, April 1993.

39. M.F. Wheeler, "A Parallel Numerical Model for Subsurface Contaminant Transport with Biodegradation Kinetics," MAFELAP Conference, Brunel University, invited speaker, April 26-29, 1993.

40. M.F. Wheeler, "Grand Challenge Problems in Porous Media," High Performance CompuPCC: Meeting, Pittsburgh, PA, May 3-6, 1993.

41. M.F. Wheeler, "A Parallel Multicomponent Two-phase Simulation with Biological and Chemical Kinetics," AGU National Meeting, Baltimore, MD, May 24-27, 1993.

42. M.F. Wheeler, "Parallel Algorithms for Modeling Multiphase Flow and Transport," Congress of the American Physical Society, Albuquerque, June 1-4, 1993.

43. M.F. Wheeler, "Domain Decomposition Algorithms for Partial Differential Equations," Computer Science Department Colloqium Presentation, University of Illinois, Urkana, IL, September 1993.

44. M.F. Wheeler, "Mixed Characteristic Method Fluids," Domain Decomposition Methods fo: Porous Media Meeting, Pennsylvania State University, University Park, Pennsylvania, October 1993.

45. M.F. Wheeler, "Modeling Adsorption and Bioremediation in Porous Media," Department of Mathematics, University of Arizona, Tucson, Arizona, November 1993.

46. T. Arbogast, "Logically rectangular mixed methods for groundwater flow and transport on general geometry," the Tenth International Conference on Computational Methocs in Water Resources, Heidelberg, Germany, July, 1994.

47. T. Arbogast, "Mathematical simulation of flow in porous media," Joint American Mathematical Society \& Mathematical Association of America Invited Address, Mathfest, Minneapolis, Minnesota, August, 1994.

48. T. Arbogast, "Mixed finite element methods as finite difference methods on general geometry, Sociedade Brasileira de Matemática Aplicada e computa- 
cional (SBMAC), XVII Crongresso Nacional de Matemática Aplicada e Computacional CNMAC, 94, Vitória, ES, Brasil, August-September, 1994.

49. T. Arbogast, "Sup«rconvergent cell-centered finite difference mixed methods for flow through geometrically heterogeneous porous media," Society of Engineering Science i1st Annual Technical Meeting, Texas A\&M University, College Station, Texas, October, 1994.

50. C. Dawson, "Modiling Nonlinear Adsorption in Contaminant Transport," Workshop on Finite Elements in Environmental Problems, University of Texas at Austin, March 1994.

51. C. Dawson, "Simulation of Groundwater Remediation," RCI Ltd. Symposium on High Performarce Computing in Energy and the Environment, Houston, March 1994.

52. C. Dawson, "Domain Decomposition Methods for Elliptic and Parabolic Equations," Numerical Analysis Colloquium, University of Chicago, May 1994.

53. C. Dawson, "Asymptotic Behavior of Solutions to Nonlinear Contaminant Transport Problems," Computational Methods in Water Resources '94, Heidelberg, Germany, July 1994.

54. M.F'. Wheeler, "Parallel Domain Decomposition Methods for Porous Media Problems" and "HPCC Grand Challenge Problems in Reservoir Engineering and Groundwater," Center for Research on Parallel Computation Annual Meeting, California Institute of Technology, Pasadena, California, January 1994.

55. M.F. Wheeler, "Parallel Algorithms for Modeling Flow in Porous Media," Louisiana State University Terraflop Mardi Gras Conference, Baton Rouge, Louisiana, Februajy 1994.

56. M.F. Wheeler, "Mathematical Modeling in Flow in Porous Media," BAM Conference, University of Sheffield, Sheffield, England, April 1994.

57. M.F. Wheeler, "Mathematical Models for Porous Media," Barkley Rosser Lecture, University of Wisconsin, Madison, Wisconsin, May 1994. 
58. M.F. Wheeler, "Mathematical Flow in Porous Media Models," IBM, T.J. Watson Center, Physics Division, May 19, 1994.

59. M.F. Wheeler, "A Nonlinear Mixed Finite Element Method for a Degenerate Parabolic Equation Arising in Flow in Porous Media," Transport in Porous Media Symposium, International Conference on Nonlinear Dynamics and Pattern Formation in the Natural Environment, ICPF'94 Leeuwenhorst Congress Center, Noordwijkerhout, the Netherlands, July 4-7, 1994.

60. M.F. Wheeler, "Transport, Bioremediation, Radionuclide Decay and Geochemistry," DOE Fieview, Washington, DC, July 13, 1994.

61. M.F. Wheeler, "A Parallel Multiphase Numerical Model for Subsurface Contaminant Transport with Biodegradation Kinetics," X International Conference on Computational Methods in Water Resources, Heidelberg, Germany, July 19-22, 1994.

62. M.F. Wheeler, "Logically Rectangular Mixed Methods for Groundwater Flow and Transport on General Geometry," X International Conference on Computational Methods in Water Resources, Heidelberg, Germany, July 19-22, 1994.

53. M. F. Wheeler, "A. perallel mitiphase numerical model for subsurface contaminant transporl, with biodegradation kinetics," at the Computational Methods in Geosciences Porous Medium Symposium, SIAM Annual Meeting, San Diego, July 26, $19 ! 34$.

64. M.F. Wheeler, "Role of Computations in Energy and Environment," Mathematical and Computational Sciences Awareness Workshop, Rice University, July 27, 1994.

65. M.F. Wheeler, "Modeling Flow in Porous Media on Distributive Memory Machines," Plenary Lecture, Numerical Modeling in Continuum Mechanics, Theory, Algorithrss, Applications, Prague, Czech Republic, Charles University, August 22-25, 1994.

66. M.F. Wheeler, "Flow in Porous Media Parallel Computation Project," Arctic Region Supercomjuting Center and the University of Alaska at Fairbanks, 
October 1994.

67. M.F. Wheeler, "Parallel Algorithms for Modeling Flow in Porous Media," The University of Texas Computational and Applied Mathematics Speaker, October 1994.

68. M.F. Wheeler, T. Arbogast, C.N. Dawson, and P.T. Keenan, Exhibitor for the Center for Research on Parallel Computation and the Center for Subsurface Modeling c,t the Society of Petroleum Engineers Petroleum Computer Conference, Houston, Texas, June, 1995.

69. T. Arbogast, "A nonlinear mixed finite element method for a degenerate parabolic equation arising in flow in porous media," Third SIAM Conference on Mathematical c.nd Computational Issues in the Geosciences, San Antonio, Texas, February, 1995.

70. T. Arbogast, "Mathematical simulation of flow in porous media," Texas Institute for Compuliational and Applied Mathematics (TICAM), University of Texas, Austin, Texas, March, 1995.

71. T. Arbogast, "The application of mixed finite element methods to subsurface simulation," First GAMM Seminar on Modelling and Computation in Environmental Sciences, University of St, oftgart, Stuttgart, Germany, October, 1995.

72. C. Dawson, "Numerical Simulation of Large Time Behavior of Solutions for Nonlinear Adsorp:ion in Contaminant Transport," Third SIAM Conference on Geosciences, San Antonio, February 1995.

73. C. Dawson, "Numerical Methods for Flow Through Porous Media," TICAM Seminar, Universi $\mathrm{y}$ of Texas at Austin, March 1995.

74. C. Dawson, "Mocleling of Groundwater Cleanup," Dept. of Aerospace Engineering and Engineering Mechanics, University of Texas at Austin, April 1995.

75. C. Dawson, "Upwind Mixed Methods for Advective Transport with Variable Time Stepping," Conference on Advances and Trends in Computational and Applied Mathematics, University of Texas at Austin, April 1995. 
76. C. Dawson, "Problems in Remediation of Contaminated Porous Media," Program in Environmental Fluid Dynamics Colloquium, Arizona State University, Sept. 1995.

77. M.F. Wheeler, "Logically Rectangular Mixed Methods for Darcy Flow on General Geometry:" 13th Symposium on Reservoir Simulation, San Antonio, Texas, February 1995.

78. M.F. Wheeler, "A Parallel Multiphase Model for Subsurface Transport with Biological and Chemical Kinetics," University of Vermont, March 1995.

79. M.F. Wheeler, "Computational Methods for Multiphase Flow and Reactive Transport Problems Arising in Subsurface Contaminant Remediation," TICAM Symposium on Advances and Trends in Computational and Applied Mathematics, April 1995.

80. M.F. Wheeler, "Parallel Algorithms for Modeling Multiphase Flow and Transport in Porous Media," Glimm '95 Conference, Stony Brook, New York, April 1995.

81. M.F. Wheeler, "Mixed Finite Element Methods for Modeling Flow and Transport in Porous Media," Mathematical Modeling of Flow through Porous Media Conference, St. Ettienne, France, May 1995.

82. M.F. Wheeler, "New Computational Approaches for Chemically Reactive Transport in Porous Media," New Generation Environmental Models Computational Methods, U.S. EPA Sponsors, Bay City Michigan, August 8, 1995.

83. M.F. Wheeler, "Advanced Numerical Models for Treating Porous Media Geology," Michigan Institute of Technology, Hoboken, Michigan, August 10, 1995.

84. M.F. Wheeler, "New Generation Simulators for Modeling Subsurface and Surface Flows; Mixed Finite Element Methods for Partial Differential Equations," "Parallel Algorithms for Permeable Media," and "Frontiers in Science," Texas A\&M University, College Station, Texas, November 1995.

85. Ivan Yotov, "Mixed finite elements for elliptic problems with tensor coefficients as cell-centered finite differences", Texas Finite Element Circus, Texas 
A\&M University, Mlar. 1995.

86. T. Arbogast, "Mix€d finite element methods on multi-block domains," at the Mathematisches Fcrschungsinstitut Oberwalfach meeting on Porous Media, organized by J. Diouglas, Jr., U. Hornung, and P. Knabner, Oberwalfach, Germany, February-March, 1996.

87. T. Arbogast, "Finise difference or volume methods for subsurface simulation arising from mixed finite elements," Pacific Northwest National Laboratory, Richland, Washington, September, 1996.

88. C. Dawson, "A Summary of Results on Asymptotic Behavior of Solutions to Nonlinear Contaminant Transport Problems," Workshop on Mathematical Problems in Flow 'Through Porous Media, Oberwolfach, Germany, February 1996.

89. M.F. Wheeler, "Energing New Algorithms for Parallel Computation in Subsurface and Surface Flows," Institute for Geophysics, The University of Texas at Austin, Jan. 19, 1996.

90. M.F. Wheeler, "Pacallel Algorithms for Modeling Multiphase Flow and Transport in Porous Media," Geology Seminar, The University of Texas, January $30,1996$.

91. M.F. Wheeler, "Modeling Activities at the Center for Subsurface Modeling," Bureau of Economic Geology, Austin, Texas, January 31, 1996.

92. M.F. Wheeler, "Modeling Multiphase Flow and Transport with Biological and Chemical Kinetics," German Mathematical Institute, Oberwolfoch, Germany, February 26 - March 2, 1996.

93. M.F. Wheeler, "Inupact of Computation on Modeling in Porous Media," NSF CISE Site Visit, Computer Science Department, March 4, 1996.

94. M.F. Wheeler, "Impact of Computation on Science and Engineering," AAAS Meeting, The University of Texas at Austin, Austin, March 6, 1996.

95. M.F. Wheeler, "N:merical Algorithms for Grand Challenge Problems," NSF Workshop on Grand Challenge Problems, NSF, Arlington, Virginia, March $21,1996$. 
96. M. Wheeler, "Mathematical Modeling of Subsurface and Surface Flow," University of Maryland Computational Science and Engineering Meeting, College Park, Maryland, March 23, 1996.

97. M.F. Wheeler, "Ernerging Parallel Computational Methodologies," University of Central Florida, Orlando Florida, April 1, 1996.

98. M.F. Wheeler, "Algorithms for Modeling Subsurface and Surface Flows," University of Central Florida, Orlando, Florida, April 2, 1996.

99. M.F. Wheeler, "Parallel Algorithms for Subsurface Flow," Computer Science Workshop, The Ur.iversity of Texas at Austin, April 22, 1996.

100. M.F. Wheeler, "Mathematical Modeling of Multiphase Flow in Porous Media," Modeling and Computation for Applications in Science and Engineering, Northwestern University, Evanston, Illinois, May 3-4, 1996.

101. M.F. Wheeler, "Subsurface and Surface Modeling at the Center for Subsurface Modeling at The University of Texas," NSF Center for Research in Parallel Computation Annual Meeting, Argonne National Laboratory, Chicago, Illinois, May 16, 1996.

102. M.F. Wheeler, "Subsurface and Surface Flow Simulation," 12th Candian Symposium of Fltid Dynanics, Winnipeg, Manitoba, Canada, May 29-31, 1996.

103. M. Wheeler, "Modeling Multicomponent, Multispecies, Multiphase Flow and Transport in Porous Media," 10th Conference on Mathematics of Finite Elements and Applications, Brunel University, Uxbridge, Middlesex, UK, June 25-28, 1996.

104. M.F. Wheeler, "Mixed Finite Element Methods with Nonmatching Grids for Partial Differentiall Equations," SIAM Annual Meeting, Kansas City, Missouri, July $23,19 \subseteq 6$.

105. M.F. Wheeler, "Modeling Activities at The Center for Subsurface Modeling at The University of Texas at Austin," Center for Research on Parallel Computation Interim Site Visit, Rice University, August 1996. 
106. Ivan Yotov, "Logically rectangular mixed methods for flow in irregular, heterogeneous domains", Eleventh International Conference on Computational Methods in Water Resources, Cancún, México, July 1996.

107. T. Arbogast, "A non-mortar mixed finite element method for elliptic problems on non-matching multiblock grids," Interdisciplinary Symposium on Advances in Computational Mechanics, The University of Texas at Austin, Austin, Texas, January, 1997.

108. T. Arbogast, "A non-mortar mixed finite element method for elliptic problems on non-matching multiblock grids," at the Finite Element Rodeo, The University of Texas; at Austin, Austin, Texas, February-March, 1997.

109. T. Arbogast, "Mixed Finite Element Methods on Non-Matching Multiblock Grids," Spring Southeastern Sectional Meeting of the American Mathematical Society, Memphis, Tennessee, March, 1997.

110. T. Arbogast, "Mixəd finite elements on multiblock grids for subsurface flow," Third IMACS International Symposium on Iterative Methods in Scientific Computation, Jackson Hole, Wyoming, July 1997.

111. S. Bryant, "Coupled geochemistry and bioreactions for remediation modeling," AGU Spring Meeting 1997, Baltimore, MD, 27-30 May 1997.

112. S. Bryant, "Redox stability: numerical and applied aspects," 4th SIAM Conf. on Mathematical and Computational Issues in the Geosciences, Albuquerque, NM, 16-19 June 1997.

113. S. Bryant, "Application of the interior point algorithm in reactive transport simulation" and "Parallel numerical algorithms for reactive transport," Workshop on Subsurface Reactive Transport Modeling, Pacific Northwest National Laboratory, Richland WA, 29 Oct.-1 Nov. 1997

114. M.F. Wheeler, "Domain Decomposition Methods for Partial Differential Equations," tutorial, Vaterways Experiment Station, Vicksburg, February 3-5, 1997.

115. M.F. Wheeler, "A Parallel Multiphase Numerical Model for Subsurface Contaminant Transport with Biodegradation and Chemical Kinetics," 1997 AAAS 
Annual Meeting and Science Innovation Exposition, Seattle, Washington, February 13-18, 1997.

116. M.F. Wheeler, "Dcmain Decomposition Methods for Subsurface and Surface Flow," University of Houston Workshop on Computational Science Applications, University of Houston, February 16, 1997.

117. M.F. Wheeler, "Multiphase Flow and Transport in Porous Media," High Performance Computing 1997, Grand Challenges in Computer Simulation, The Society for Computer Simulation International, Atlanta, Georgia, April 6-10, 1997.

118. M.F. Wheeler, "Environmental Quality Management Activities at the University of Texas at Austin," DOD Performance Evaluation Training Review, Vicksburg Waterway Research Center, Vicksburg, Mississippi, April 15-16, 1997.

119. M.F. Wheeler, "Parallel Algorithms for Multiphase Flow," Computational Science for the 21st Century, Tours, France, May 5-7, 1997.

120. M.F. Wheeler, "Domain Decomposition Methods for Partial Differential Equations," tutorial, Center for Research on Parallel Computation, Rice University, Waterways Experiment Station, Vicksburg, May 18, 1997.

121. M.F. Wheeler, "Center for Subsurface Modeling Activities in 1997," Center for Research in Parallel Computation Annual Meeting, May 19, 1997.

122. M.F. Wheeler, "Mathematical Modeling in Porous Media," tutorial, INRIA, Versilles, France, June 2-5, 1997.

123. M.F. Wheeler, "Párallel Algorithms for Subsurface Flow and Transport with Biological and Chemical Kinetics" and "Conservative Algorithms for Surface and Subsurface Flow," V SIAM Geosciences Meeting, Albuquerque, New Mexico, June 16-18, 1997.

124. M.F. Wheeler, "Domain Decomposition for Modeling Subsurface and Surface Flow," and "Multigrid on the Interface for Mixed Finite Element Methods on Non-Matching Multiblock Grids," Tenth International Conference on Domain Decomposition Methods, Boulder, Colorado, August 10-14, 1997. 
125. T. Arbogast, "Upscaling through numerical subgrid-scale approximations," at the Finite Element Rodeo, Texas A\&M University, College Station, Texas, March, 1998.

126. T. Arbogast, "Nurnerical simulation of subsurface flow and reactive transport" (with Mary 1 . Wheeler), Exploring the interface between the sciences and mathematical sciences, Committee on strengthening the linkages between the sciences and mathematical sciences, National Research Council, Washington, D.C., March 25-26, 1998.

127. S. Bryant, "Efficient parallel computation strategies for reactive transport models," AGU Spring Meeting, Boston, MA, 26-29 May 1998.

128. S. Bryant, "Efficient computation strategies for large-scale remediation simulation," Environmental Solutions Program Spring Research Review, Austin, TX, 23-24 April 1!998.

\subsection{References}

[1] C. Dawson, Godun'ov-mixed methods for advection-diffusion equations in multidimensions, SIAM. J. Numer. Anal., 30 (1993), 1315-1332.

[2] C. Dawson and M. F. Wheeler, An operator-splitting method for advectiondiffusion-reaction problems, in MAFELAP Proceedings VI, J. A. Whiteman, ed., Academic Presis (1988), 463-482.

[3] C. Dawson and M. F. Wheeler, Time-splitting methods for advectiondiffusion-reaction fquations arising in contaminant transport, in Proceedings, ICIAM '91, R. O'JMalley, ed., SIAM (1992), 71-82.

[4] A. S. El-Bakry, R. A. Tapia, T. Tsuchiya, and Y. Zhang, On the formulation and theory of the Newton interior-point method for nonlinear programming, Journal of Optimization Theory and Applications, 89 (1996), 507-541.

[5] R. Glowinski and M. F. Wheeler, Domain decomposition and mixed finite element methods for alliptic problems, in First International Symposium on Domain Decomposition Methods for Partial Differential Equations, R. Glowinski et al., eds., SIAM, Philadelphia (1988), 144-172. 
[6] G. Yeh and V. Tripathi, A model for simulating transport of reactive multispecies components: model development and demonstration, Water Resources Research, 27 (1991), 3075-3094. 
ORNL/TM-13443

\section{INTERNAL DISTRIBUTION}

1. A. S. Bland

2. E. F. D'Azevedo

3. G. K. Jacobs

4. K. L. Kliewe::

5-9. G. Mahinthakumar
10. C. E. Oliver

11. B. A. Riley

12. Laboratory Records - RC

13-14. Laboratory Records Department/OSTI

15. Central Research Library

\section{EXTERNAL DISTRIBUTION}

16. Michael A. Celia, Department of Civil Engineering and Operations Research, Princeton University, Princeton, NJ 8544

17. Richard E. Ewing, College of Science, Texas A\&M University, College Station, TX 77843-3404

18. James Glimm, Department of Applied Mathematics and Statistics, P-138A Mathematics Building, Stony Brook, NY 11794-360

19. Daniel A. Hitchcock, ER-31, Acting Director, Mathematical, Information, and Computation:al Sciences Division, Office of Computational and Technology Research, Office of Energy Research, Department of Energy, Washington, DC 20585

20. Frederick A. Howes, ER-31, Mathematical, Information, and, Computational Sciences Division, Ofice of Computational and Technology Research, Office of Energy Research, Dejartment of Energy, Washington, DC 20585

21. Tom Kitchen;, ER-31, Mathematical, Information, and, Computational Sciences Division, Office of Computational and Technology Research, Office of Energy Research Depariment of Energy, Washington, DC 20585

22. David B. Nelson, ER-30, Associate Director, Office of Energy Research, Director, Office of Computational and Technology Research, Department of Energy, Washington, DC 20585

23. Ronald F. Peierls, Department of Applied Science, Analytical Sciences Division (EE), Bldg. 490D, Brookhaven National Laboratory, Box 5000, Upton, NY 119735000

24. Robert C. Sharpley, Department of Mathematics, University of South Carolina, Columbia, SC, 29208

25. Mary F. Wheeler, Texas Institute for Computational and Applied Mathematics, The University of Texas at Austin, Taylor Hall 2.400 / UT Mail Code C0200, Austin, TX 78712 